\title{
Histopathology and biochemistry analysis of the interaction between sunitinib and paracetamol in mice
}

\author{
Adeline YL Lim ${ }^{1 \dagger}$, Ignacio Segarra ${ }^{2^{*}+}$, Srikumar Chakravarthi ${ }^{3 \dagger}$, Sufyan Akram ${ }^{1 \dagger}$, John P Judson ${ }^{1 \dagger}$
}

\begin{abstract}
Background: Sunitinib, a tyrosine kinase inhibitor to treat GIST and mRCC may interact with paracetamol as both undergo P450 mediated biotransformation and P-glycoprotein transport. This study evaluates the effects of sunitinib-paracetamol coadministration on liver and renal function biomarkers and liver, kidney, brain, heart and spleen histopathology. ICR male mice ( $n=6$ per group/dose) were administered saline (group- $A$ ) or paracetamol $500 \mathrm{mg} / \mathrm{kg}$ IP (group-B), or sunitinib at 25,50,80, 100, $140 \mathrm{mg} / \mathrm{kg} \mathrm{PO} \mathrm{(group-C)} \mathrm{or} \mathrm{coadministered} \mathrm{sunitinib} \mathrm{at} \mathrm{25,}$ $50,80,100,140 \mathrm{mg} / \mathrm{kg}$ PO and paracetamol IP at fixed dose $500 \mathrm{mg} / \mathrm{kg}$ (group-D). Paracetamol was administered $15 \mathrm{~min}$ before sunitinib. Mice were sacrificed $4 \mathrm{~h}$ post sunitinib administration.

Results: Group-A serum ALT and AST levels were $14.29 \pm 2.31 \mathrm{U} / \mathrm{L}$ and $160.37 \pm 24.74 \mathrm{U} / \mathrm{L}$ respectively and increased to $249.6 \pm 222.7 \mathrm{U} / \mathrm{L}$ and $377.1 \pm 173.6 \mathrm{U} / \mathrm{L}$ respectively in group-B; group-C ALT and AST ranged 36.75$75.02 \mathrm{U} / \mathrm{L}$ and 204.4-290.3 U/L respectively. After paracetamol coadministration with low sunitinib doses (group-D), ALT and AST concentrations ranged 182.79-221.03 U/L and 259.7-264.4 U/L respectively, lower than group-B. Paracetamol coadministration with high sunitinib doses showed higher ALT and AST values (range 269.6-349.2 U/L and 430.2-540.3 U/L respectively), $p<0.05$. Hepatic histopathology showed vascular congestion in group-B; mild congestion in group- $C$ (but lesser than in group- $B$ and $D$ ). In group-D, at low doses of sunitinib, lesser damage than in group-B occurred but larger changes including congestion were observed at high sunitinib doses. BUN levels were higher $(p<0.05)$ for group-B $(33.81 \pm 5.68 \mathrm{mg} / \mathrm{dL})$ and group-D (range $35.01 \pm 6.95 \mathrm{U} / \mathrm{L}$ to $52.85 \pm$ $12.53 \mathrm{U} / \mathrm{L}$ ) compared to group-A $(15.60 \pm 2.17 \mathrm{mg} / \mathrm{dL}$ ) and group-C (range $17.50 \pm 1.25 \mathrm{U} / \mathrm{L}$ to $26.68 \pm 6.05 \mathrm{U} / \mathrm{L}$ ). Creatinine remained unchanged. Renal congestion and necrosis was lower in group- $C$ than group-B but was higher in group-D ( $p>0.05$ ). Mild cardiotoxicity occurred in groups B, C and D. Brain vascular congestion occurred at high doses of sunitinib administered alone or with paracetamol. Hepatic and renal biomarkers correlated with histopathology signs.

Conclusions: Paracetamol and sunitinib coadministration may lead to dose dependent outcomes exhibiting mild hepatoprotective effect or increased hepatotoxicity. Sunitinib at high doses show renal, cardiac and brain toxicity. Liver and renal function monitoring is recommended.
\end{abstract}

\section{Background}

Drug-drug interactions (DDIs) defined as an increase or decrease in the clinical effect of a given drug due to interference by another drug, is a significant cause of

\footnotetext{
* Correspondence: segarra100@gmail.com

+ Contributed equally

2Department of Pharmaceutical Technology, School of Pharmacy and Health Sciences, International Medical University, Jalan 19/155B, Bukit Jalil, 57000

Kuala Lumpur, Malaysia

Full list of author information is available at the end of the article
}

morbidity and mortality worldwide [1]. DDIs may result in adverse clinical events, by decreasing the therapeutic effect of a drug or by enhancing drug toxicity [2].

Cancer patients present high risk of DDIs as polypharmacy for the treatment of cancer as well as other related syndromes is common [3]. They are also very susceptible to pain, with moderate or severe pain prevalent in at least $50 \%$ of cancer patients $[4,5]$. Severe DDIs have been observed between anti-cancer and pain management drugs. Some patients treated with imatinib, a
Ciomed Central

() 2010 Lim et al; licensee BioMed Central Ltd. This is an Open Access article distributed under the terms of the Creative Commons Attribution License (http://creativecommons.org/licenses/by/2.0), which permits unrestricted use, distribution, and reproduction in any medium, provided the original work is properly cited. 
generally well-tolerated chemotherapeutic agent, have experienced renal and hepatic toxicity, which was increased and fatal in some cases upon coadministration with paracetamol [6]. Mechanistic studies in animal models showed changes in imatinib pharmacokinetic and tissue penetration profiles [7] but most importantly, an increased of irreversible hepatotoxicity was observed when both drugs were co-administered [8]. The importance of interactions with paracetamol is also relevant to sunitinib: a patient with relapsed metastatic gastrointestinal stromal tumour (GIST) treated with sunitinib and taking also paracetamol and levothyroxine, developed acute liver failure with fatal outcome [9].

Sunitinib (sunitinib malate; SU11248, SUTENT ${ }^{\oplus}$ ) is a novel oral multitargeted tyrosine kinase inhibitor that received regular approval from the United States FDA for the treatment of GIST as well as advanced renal cell carcinoma (RCC) after progression [10] or intolerance to imatinib mesylate $[11,12]$. Sunitinib inhibits various receptor tyrosine kinases such as the vascular endothelial growth factor receptors (VEGFR) [13], the foetal liver tyrosine kinase receptor 3 (FLT3) [14], stem-cell factor receptor (c-KIT) [15], platelet-derived growth factor receptors PDGFR $\alpha$ and PDGFR $\beta$ [16], and colony stimulating factor type 1 receptor (CSF-1R) [17]. Consequently, there is inhibition of angiogenesis, tumor growth and metastasis $[18,19]$.

In humans, the maximum plasma concentration is reached 6-12 h after dosing, shows good tissue distribution, dose proportionality at the range $25-100 \mathrm{mg}$, and is highly bound to albumin (95\%). Sunitinib is metabolized primarily by the cytochrome P450 3A4 to form main active metabolite SU12662 that is further metabolized by CYP3A4 [11]. Sunitinib and its metabolite, which is also highly bound to plasma proteins (90\%), have half-lives of 40-60 h and 80-110 h respectively, $61 \%$ of the sunitinib dose is eliminated in the faeces and around $16 \%$ is recovered unchanged in urine $[11,17]$. Pharmacokinetic studies in mice have shown that sunitinib is readily absorbed, presents dose proportionality and the maximum concentration is achieved within 0.5 to $6 \mathrm{~h}$. Both sunitinib and the main metabolite (SU12662) are highly bound to mouse plasma proteins (91\% and $95 \%$ respectively) with the fraction unbound independent of the concentration. The elimination halflife in mice is 1.5 to $7.6 \mathrm{~h}$ after oral administration [20].

Although the therapeutic benefits of sunitinib are great, sunitinib treatment has a significant number of side effects including fatigue [21], hypertension [11,22], cardiac dysfunction [23], thyroid dysfunction [23], hand food skin reaction $[19,24]$, hair depigmentation [19], asthenia [25], haematologic toxicity [11], and less commonly posterior reversible encephalopathy [26], cardiotoxicity and hypothyroidism [27] and tumour lyses syndrome [28]. In addition, sunitinib treatment also caused treatment-emergent laboratory abnormalities such as a rise in serum alanine transaminase (ALT), aspartate transaminase (AST) as well as serum creatinine concentrations in GIST and $\mathrm{mRCC}$ patients which was mainly Grade 1 and 2 in severity $[11,12]$.

Sunitinib is likely to present a variety of metabolism based drug-drug interactions Biotransformation of sunitinib to form the pharmacologically active N-desethyl metabolite, SU12662 is affected by inhibitor or inducers of CYP3A4 [11]. Strong CYP3A4 inhibitors such as ketoconazole have shown to decrease the metabolism of sunitinib and to increase plasma sunitinib concentrations [13]. Similarly, CYP3A4 inducers (e.g. rifampin) may decrease sunitinib plasma concentrations when the inducer and sunitinib are co-administered together which lead to subtherapeutic sunitinib levels [20]. Furthermore, there are some indications that CYP1A1 and 1A2 may also play a role in sunitinib biotransformation [29]. Thus, if it is necessary to concurrently administer sunitinib and a CYP3A4 inhibitor or inducer, it is recommended that the dose of sunitinib should be adjusted (decreased or increased) and that diligent monitoring for toxicity be carried out [11].

Given the nature of the cancer treatment, cancer patients are likely to be administered pain management drugs $[2,4]$. In this study, we used a mouse model to evaluate the safety and toxicity upon the drug-drug interaction between sunitinib and paracetamol, a widely used over the counter analgesic and antipyretic drug. Though, paracetamol is regarded as a safe drug at therapeutic doses; at larger or chronic doses may result in severe liver and renal injuries [30], including changes in alkaline phosphatase (ALP), AST, ALT and creatinine plasma levels [31] which could be additive to those of sunitinib [10]. Small amounts of paracetamol $(\sim 5 \%)$ undergo $\mathrm{P} 450$ mediated oxidation to a reactive electrophilic intermediate, $\mathrm{N}$-acetyl-p-benzoquinoneimine (NAPQI) [32]. Several P450 isoforms including CYP3A1, $2 \mathrm{E} 1,1 \mathrm{~A} 2$ and $2 \mathrm{D} 6$ are implicated in the activation of paracetamol to NAPQI in both humans and rodents [33]. Furthermore to the hepatotoxicity, potential overlapping sunitinib-paracetamol toxicity could also include renal insufficiency [29] and cardiotoxicity [34].

The current study aims to evaluate the toxicity associated with the coadministration of sunitinib and paracetamol in mice. A histopathology assessment of the liver, kidney, spleen, heart and brain is carried out and correlated with the plasma levels of the biochemical markers AST, ALT, creatinine and urea.

\section{Methods \\ Materials}

Stock solution of paracetamol (Fluka, France) was prepared in reversed osmosis (RO) water at $30 \mathrm{mg} / \mathrm{mL}$. 
The paracetamol solution was vortex mixed, sonicated $(25 \mathrm{~min})$ and kept warm briefly $\left(50^{\circ} \mathrm{C}\right)$ prior to IP administration to mice. Sunitinib malate (Zhejiang Esun Chemical Co. Ltd., China) was diluted in RO water to $15 \mathrm{mg} / \mathrm{mL}$, vortex mixed, sonicated ( $25 \mathrm{~min}$ ), protected from light at room temperature until PO administration.

\section{Animals and experimental protocols}

Male ICR mice of similar age (8-12 weeks) and weight (25-35 g) were obtained from University Putra Malaysia and housed at the International Medical University (IMU) animal holding facility with $12 \mathrm{~h}$ light cycles at $20 \pm 2^{\circ} \mathrm{C}$ for acclimatization. The experimental animals were provided food and water ad libitum. All animal procedures had been reviewed and approved by the IMU Institutional Animal Use and Ethics Committee preceding the initiation of this study.

Animals were fasted overnight prior to dose administration and randomly assigned to each of the four experimental groups. Mice in group A $(n=6)$ were administered saline; mice in group $B$ mice $(n=6)$ were administered paracetamol only, $500 \mathrm{mg} / \mathrm{kg}$ IP. Group C was further subdivided into five different dose-groups of sunitinib only treatment: $25,50,80,100$ and $140 \mathrm{mg} / \mathrm{kg}$ administered PO ( $\mathrm{n}=6$ for each dose group). Finally, mice in group D were co-administered paracetamol (500 $\mathrm{mg} / \mathrm{kg} \mathrm{IP}$ ) and sunitinib at different doses: $25,50,80$, 100 and $140 \mathrm{mg} / \mathrm{kg}$ PO ( $\mathrm{n}=6$ each dose group). A feeding needle was used to ensure the full administration of the dose. Paracetamol was administered 15 minutes before sunitinib and animals were sacrificed 4 hours post sunitinib administration by cervical dislocation. Blood was obtained via cardiac puncture, allowed to clot, centrifuged (1500 rpm, $10 \mathrm{~min}$, room temperature) and stored at $-20^{\circ} \mathrm{C}$ until analysis. The liver and kidneys were excised from the mice and processed for histology assessment.

\section{Serum biomarkers analysis}

Biochemistry analysis of serum ALT and AST was performed using standard assay kits (BiooScientific Corp., USA). The concentration in duplicate samples was measured at $340 \mathrm{~nm}$ using a microplate reader (Tecan Infinite F200). Similarly, blood urea nitrogen (BUN) and creatinine concentration were measured using specific assay kits (BioAssay Systems, USA) and measured at $490 \mathrm{~nm}$ (duplicate samples) in a Dynex OpsysMR microplate reader.

The effect of the drug combination on the biomarker levels compared to sunitinib alone treatment was assessed with the aid of SPSS 16.0 with the significance level set at $\mathrm{p}<0.05$. Independent-samples $\mathrm{t}$-test (for samples normally distributed based on Shapiro-Wilk test) for pair-wise comparison was performed at each dose of the sunitinib alone and sunitinib and paracetamol combination groups. Samples that were not normally distributed were tested using the Mann Whitney test.

\section{Histopathology assessment of tissues}

Processing of tissue samples for histology assessment followed established procedures. In brief, the tissue samples were rinsed with $0.9 \%$ saline solution, fixed in $10 \%$ formalin. Then the diagonal section of the liver, the transverse section of the kidneys and heart and the horizontal section of the spleen and the posterior section of the brain were obtained and processed (Leica TP1020, Japan) as follows: (1) $10 \%$ neutral buffered formalin for $1 \mathrm{~h}$, twice; (2) $70 \%$ alcohol for $1.5 \mathrm{~h}$; (3) $80 \%$ alcohol for $1.5 \mathrm{~h}$; (4) $90 \%$ alcohol for $1.5 \mathrm{~h}$; (5) absolute alcohol for $1.5 \mathrm{~h}$, twice; (6) xylene for $1.5 \mathrm{~h}$, twice; (7) in molten wax at $65^{\circ} \mathrm{C}$ for $2.5 \mathrm{~h}$ two changes. The processed tissues were embedded in paraffin and sectioned at 4 microns thickness, placed on frosted glass slides and dried on a $70^{\circ} \mathrm{C}$ hot plate for 30 minutes.

The tissues were stained using the hematoxylin and eosin (H\&E) stains. The sections were dewaxed in two changes of xylene ( 3 min each), hydrated in two changes of $100 \%$ ethanol, followed by $90 \%$ ethanol and $70 \%$ ethanol, for $3 \mathrm{~min}$ each, rinsed with water $(3 \mathrm{~min})$ and stained. The stained tissues were dehydrated with $70 \%$ ethanol followed by $90 \%$ ethanol, placed in two changes of $100 \%$ ethanol for 3 minutes each and cleaned with two changes of xylene (3 min each).

Histopathology changes were observed and grouped based on two main criteria: vascular changes including vessel congestion, extravasation of red blood cells and hematoma formation; and necrotic changes including necrosis, fibrosis, nuclear changes, abscesses and cell regeneration. The morphological changes were assessed semi-quantitatively, blind by two independent assessors and graded as follows: No change - 0 (no distinguishable change, $0 \%$ ); mild change - 1 (initiation of changes, up to $30 \%$ ); moderate change - 2 (patent changes, $31-60 \%$ ); severe change - 3 (wide spread changes, 61-100\%) [35]. Then, using SPSS 16.0, the Mann-Whitney test was used for pair-wise comparison between the sunitinib alone group and the combination group at each dose. The differences were considered significance if $\mathrm{p}<0.05$.

\section{Results}

The changes in toxicity associated with the coadministration of sunitinib and paracetamol were assessed at biochemistry and histopathology level. The serum concentrations of the biochemical markers ALT, AST, urea and creatinine were obtained to evaluate the liver and renal functions. In addition, the histopathological changes in the target organs such as liver, kidneys, heart, brain and spleen were semi-quantitatively graded. 


\section{Liver and renal function biomarkers}

The mean serum AST level in untreated mice (Table 1), vehicle control group was $160.37 \pm 24.74 \mathrm{U} / \mathrm{L}$ but it was 2-fold greater $(377.09 \pm 173.55 \mathrm{U} / \mathrm{L})$ in mice treated with paracetamol (Figure 1). Mice treated with increasing doses of sunitinib showed a gradual elevation of AST serum concentration (range 204.64 - $290.28 \mathrm{U} / \mathrm{L}$ ) following rising sunitinib doses. However, the pattern observed upon coadministration of sunitinib and paracetamol was different. At lower doses of sunitinib, the mean AST serum concentrations were slightly higher than those of the sunitinib alone group, but lower than the concentration found upon administration of paracetamol alone: $31.1 \%$ and $29.9 \%$ for the $25 \mathrm{mg} / \mathrm{kg}$ and 50 $\mathrm{mg} / \mathrm{kg}$ dose respectively. However, a large increase in AST concentrations were observed at the higher doses of sunitinib coadministered with paracetamol which was statistically significant at $100 \mathrm{mg} / \mathrm{kg}(\mathrm{p}<0.01)$ and 140 $\mathrm{mg} / \mathrm{kg}(\mathrm{p}<0.001)$ doses.

Similarly, the serum ALT concentrations were measured (Figure 1, Table 1). In the vehicle control group the ALT serum concentration was $14.29 \pm 2.31 \mathrm{U} / \mathrm{L}$ and it slightly increased in the sunitinib treatment group (range 36.75 - $75.02 \mathrm{U} / \mathrm{L}$ ). As expected, a large increase in serum ALT levels was observed after administration of paracetamol only $(249.60 \pm 222.72 \mathrm{U} / \mathrm{L})$ although it did not reach statistical difference with the baseline control value, probably due to the large variability. Parallel to AST, there was a significant ALT elevation in the coadministration group at $100 \mathrm{mg} / \mathrm{kg}(\mathrm{p}<0.05)$ and 140 $\mathrm{mg} / \mathrm{kg}(\mathrm{p}<0.01)$ doses of sunitinib. In addition, at lower doses of sunitinib with paracetamol coadministration, the ALT levels were found lower than those in the group that received paracetamol only: at $25 \mathrm{mg} / \mathrm{kg}$ the ALT concentration was $26.8 \%$ lower and at $50 \mathrm{mg} / \mathrm{kg}$ it was $25.2 \%$ lower. However, it did not reach statistical significance probably due to the variability in the paracetamol group.

Renal biomarkers included the blood urea nitrogen (BUN) and creatinine (Figure 1, Table 1). The BUN concentrations were slightly increased (range 17.50 $26.68 \mathrm{mg} / \mathrm{dL}$ ) after administration of sunitinib in comparison to those of baseline control group $(15.60 \pm 2.17$ $\mathrm{mg} / \mathrm{dL})$ with significant differences $(\mathrm{p}<0.05)$ with the control group at 25,80 and $140 \mathrm{mg} / \mathrm{kg}$ sunitinib doses. A significant increase in BUN concentration was observed in the group administered paracetamol only $(33.81 \pm 5.68 \mathrm{mg} / \mathrm{dL}, \mathrm{p}<0.05)$. In addition, all dose groups of the coadministration group showed differences with the respective sunitinib group dose ( $\mathrm{p}<$ 0.05). As for creatinine concentrations (Figure 1), there was no significant difference between the serum concentrations in the baseline control group $(0.529 \pm 0.044$ $\mathrm{mg} / \mathrm{dL}$ ) and those found in mice treated with increasing doses of sunitinib alone (range $0.528-0.594 \mathrm{mg} / \mathrm{dL}$ ). However, administration of paracetamol alone increased $21 \%$ the creatinine serum concentration. Finally, the combination treatment sunitinib-paracetamol did not show any significant rise in mean creatinine concentrations.

\section{Histopathology in liver tissue}

The histopathology assessment in liver was performed for all groups. Mice in the vehicle (saline) control group showed normal, well defined histological structures without any signs of vascular or inflammatory changes. The histopathology analysis of the liver revealed signs of toxicity after administration of paracetamol. This toxicity was significant $(\mathrm{p}<0.05)$ in comparison with baseline group and included mild vascular

Table 1 Mean \pm SE serum biomarker concentration for each of the study arms

\begin{tabular}{|c|c|c|c|c|c|c|}
\hline \multirow[t]{2}{*}{ Group } & \multicolumn{2}{|c|}{ Dose $(\mathrm{mg} / \mathrm{kg})$} & \multirow{2}{*}{$\begin{array}{l}\text { AST } \\
(\mathrm{U} / \mathrm{L})\end{array}$} & \multirow{2}{*}{$\begin{array}{l}\text { ALT } \\
(U / L)\end{array}$} & \multirow{2}{*}{$\begin{array}{c}\text { BUN } \\
(\mathrm{mg} / \mathrm{dL})\end{array}$} & \multirow{2}{*}{$\begin{array}{c}\text { Creatinine } \\
(\mathrm{mg} / \mathrm{dL})\end{array}$} \\
\hline & SUN & PCM & & & & \\
\hline Vehicle & - & - & $160.4 \pm 24.7$ & $14.29 \pm 2.31$ & $15.6 \pm 2.17$ & $0.529 \pm 0.044$ \\
\hline PCM & - & 500 & $377.1 \pm 173.6$ & $249.6 \pm 222.7$ & $33.81 \pm 5.68$ & $0.644 \pm 0.110$ \\
\hline \multirow[t]{5}{*}{ Sunitinib } & 25 & - & $204.6 \pm 50.3$ & $61.40 \pm 26.57$ & $20.08 \pm 2.54$ & $0.535 \pm 0.033$ \\
\hline & 50 & - & $204.4 \pm 49.4$ & $36.75 \pm 12.15$ & $17.5 \pm 1.25$ & $0.594 \pm 0.082$ \\
\hline & 80 & - & $290.3 \pm 77.7$ & $75.02 \pm 20.37$ & $19.71 \pm 0.58$ & $0.528 \pm 0.064$ \\
\hline & 100 & - & $243.0 \pm 66.4$ & $47.61 \pm 24.50$ & $17.62 \pm 0.94$ & $0.533 \pm 0.060$ \\
\hline & 140 & - & $239.5 \pm 65.9$ & $50.89 \pm 18.90$ & $26.68 \pm 6.05$ & $0.559 \pm 0.051$ \\
\hline Sunitinib & 25 & 500 & $259.7 \pm 67.4^{+}$ & $182.8 \pm 64.91^{*}$ & $38.24 \pm 6.08^{*}$ & $0.514 \pm 0.089$ \\
\hline \multirow[t]{4}{*}{$\& P C M$} & 50 & 500 & $264.4 \pm 104.9$ & $186.7 \pm 124.3$ & $38.89 \pm 8.69^{*}$ & $0.520 \pm 0.143$ \\
\hline & 80 & 500 & $430.2 \pm 163.6$ & $221.0 \pm 113.0$ & $35.01 \pm 6.95^{*}$ & $0.591 \pm 0.084$ \\
\hline & 100 & 500 & $469.8 \pm 90.3^{+*}$ & $349.2 \pm 132.4^{*}$ & $43.75 \pm 8.37^{*}$ & $0.502 \pm 0.103$ \\
\hline & 140 & 500 & $540.3 \pm 76.1^{+*}$ & $269.6 \pm 72.6^{*}$ & $52.85 \pm 12.53^{+*}$ & $0.627 \pm 0.060$ \\
\hline
\end{tabular}

$+p<0.05$ in comparison with group B (paracetamol).

${ }^{*} p<0.05$ in comparison with group $C$ (sunitinib alone). 


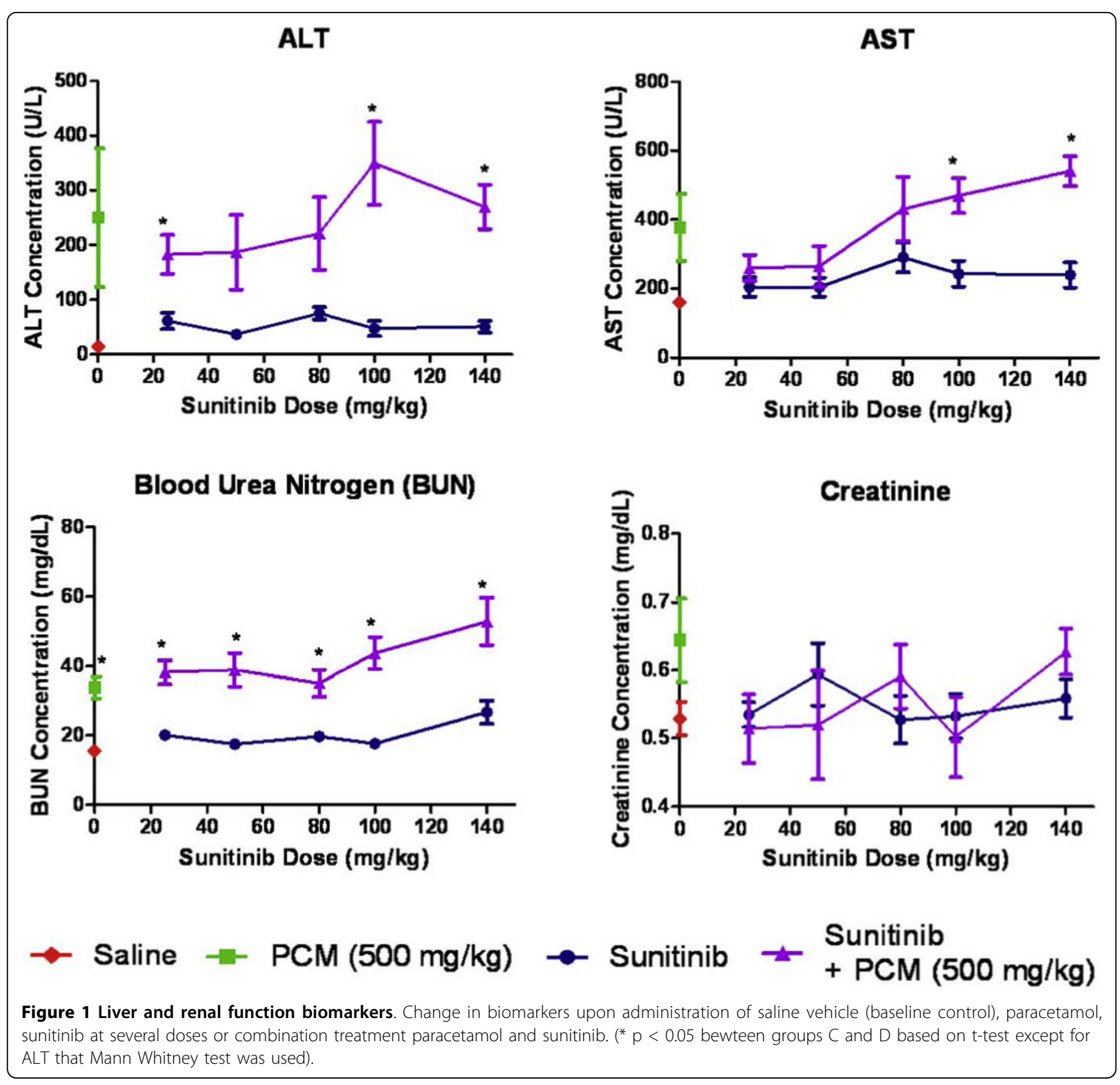

congestion and moderate inflammatory changes with congested sinusoids, nuclear changes, and centrilobular necrosis (Figure 2). Treatment with increasing doses of sunitinib alone resulted in mild vascular and inflammatory changes (not significant in comparison with baseline control) including microabscess formation and cytoplasmic condensation indicating early cellular injury (Figure 3). In the combination treatment, there was moderate to severe vascular and sinusoidal congestion, as well as inflammatory changes with extensive necrosis at high doses of sunitinib that were statistically significant in comparison with the sunitinib alone group ( $\mathrm{p}<0.05$ ) at 80,100 and $140 \mathrm{mg} / \mathrm{kg}$ (Figure 4 and 5). However, at lower doses of sunitinib coadministered with paracetamol, there were mild vascular changes comparable to those in the group treated with paracetamol and mild inflammatory changes which were even less severe than those observed after paracetamol administration (Figure 5).

\section{Renal histopathology}

Normal histology of the glomerulus and tubules was found in kidney tissue of mice that received saline vehicle only (Figure 6). Paracetamol induced mild vascular and inflammatory changes with signs of vascular congestion, tubular necrosis and glomerular atrophy, which is a 


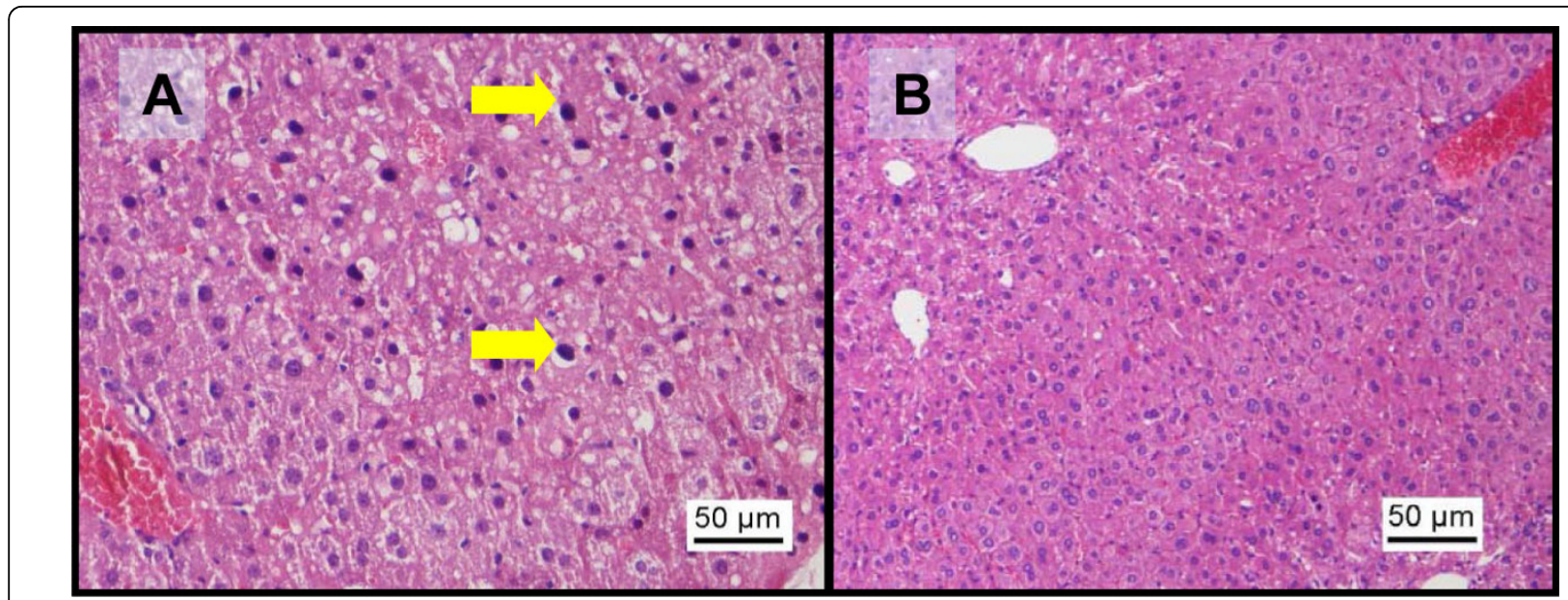

Figure 2 Histopathological changes in liver after administration of paracetamol. Representative microphotographs of liver tissue sections (H\&E staining, 200x) showing (A) nuclear pyknosis (arrows), vascular congestion and fatty change in liver parenchyma and (B) areas of centrilobular necrosis and vascular congestion involving the portal triad and dilation of central vein indicating backflow of circulation.

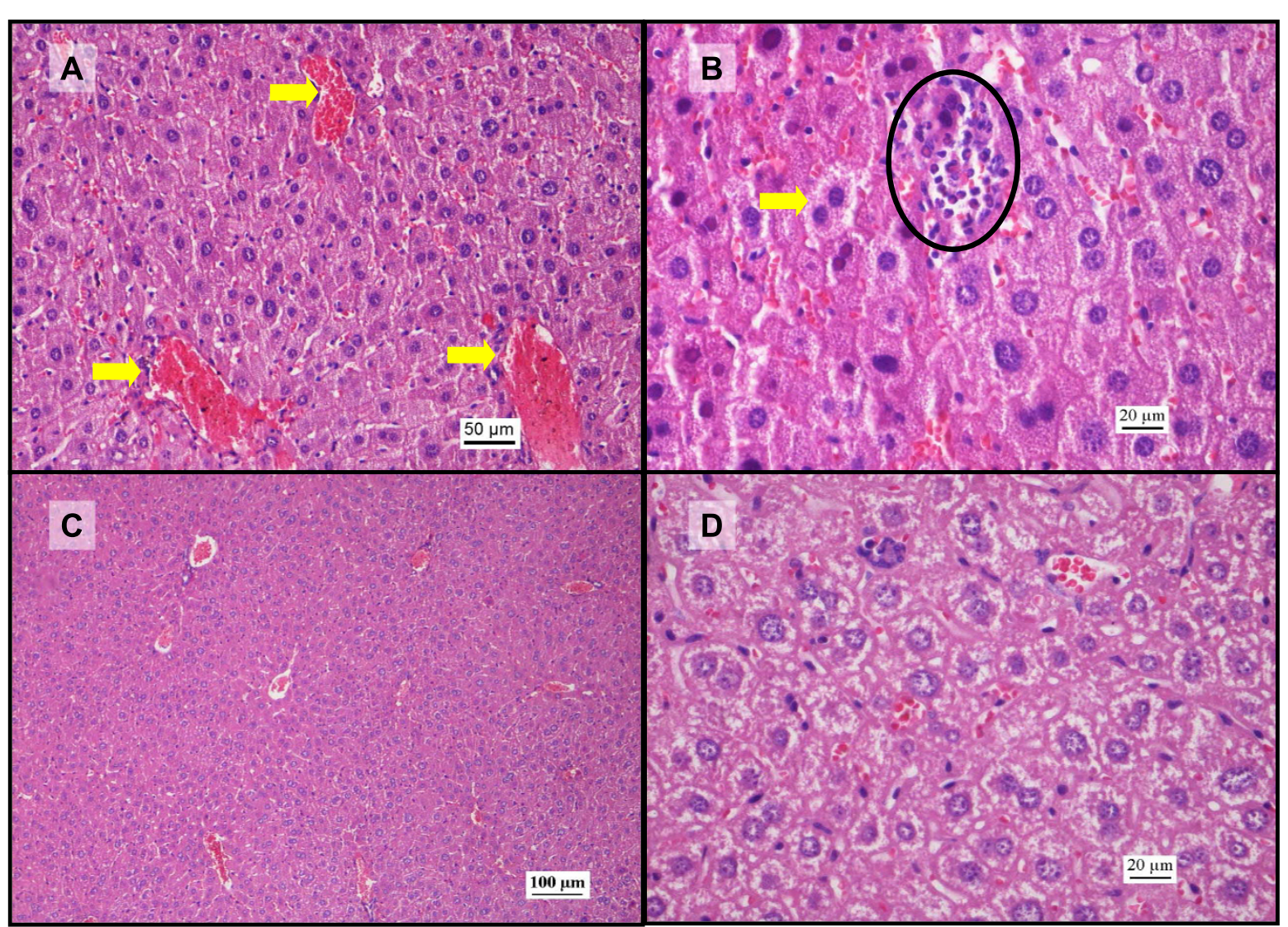

Figure 3 Histopathological changes in liver after administration of sunitinib (H\&E staining). A: Photomicrograph (200x) of liver section after administration of $25 \mathrm{mg} / \mathrm{kg}$ sunitinib showing vascular congestion (arrows) in the central veins and red blood cells pooling in the sinusoids. B: Liver section (400x) after administration of sunitinib $25 \mathrm{mg} / \mathrm{kg}$. Notice a microabscess (circle) involving a few hepatocytes with inflammatory cells and necrotic debris. Hepatocytes undergoing cytoplasmic condensation and regeneration are also observed (arrow). C: Photomicrograph (100x) from the sunitinib $80 \mathrm{mg} / \mathrm{kg}$ group showing vascular congestion involving the central veins amidst hepatocytes surrounded by dilated sinusoids. D: Photomicrograph (400x) from the sunitinib $100 \mathrm{mg} / \mathrm{kg}$ group. Notice the hepatocytes in various stages of cytoplasmic condensation, suggesting early stages of cell injury. 


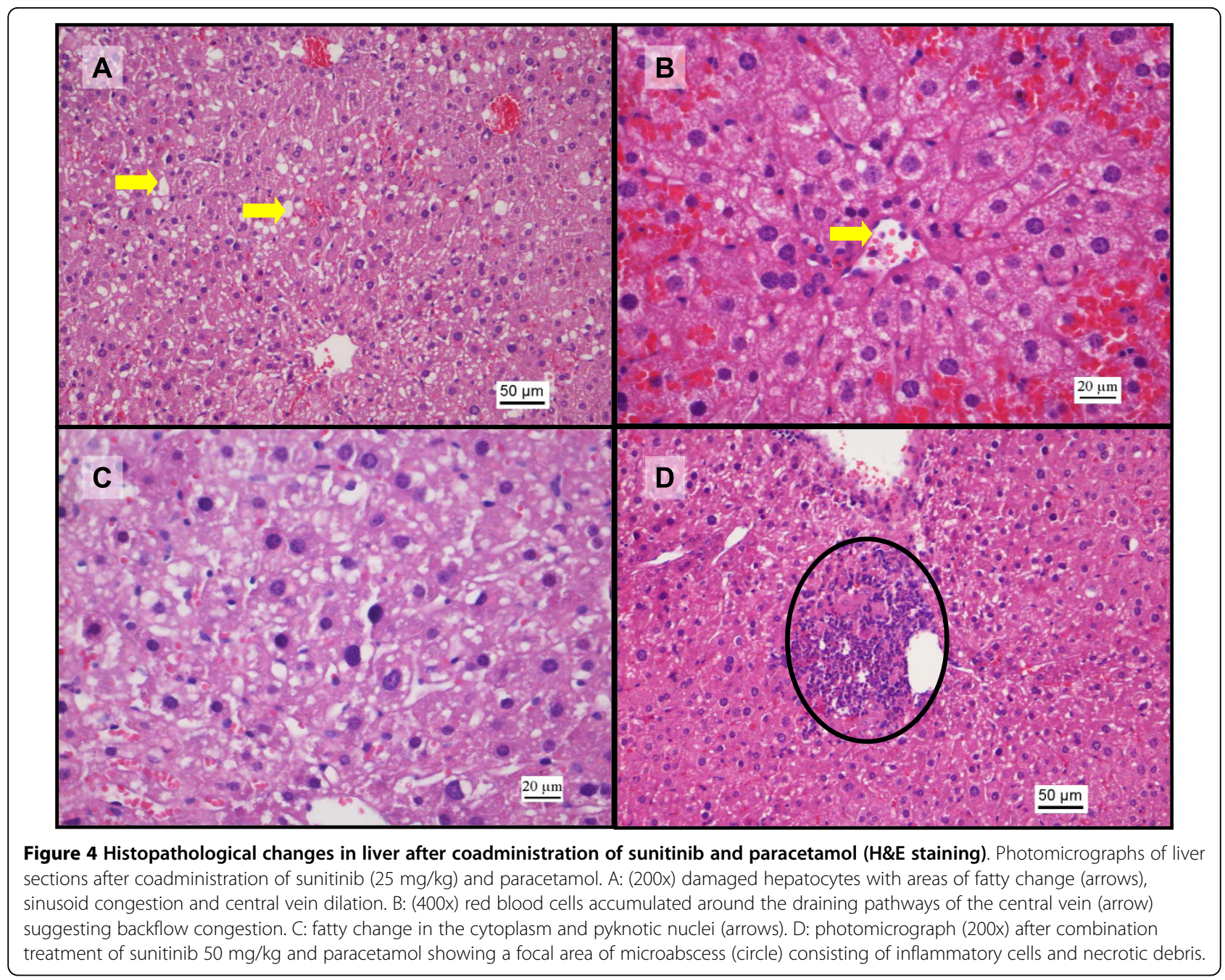

degenerative phenomenon (Figure 6). Mice treated with sunitinib alone only showed mild vascular changes in the kidneys comparable to those observed upon administration of paracetamol, but no signs of inflammatory changes were observed, except at the highest dose of sunitinib $(140 \mathrm{mg} / \mathrm{kg})$ where some tubular necrosis was noted (Figure 7). In the combination treatment group, the vascular changes increased ( $\mathrm{p}<0.05$ above $80 \mathrm{mg} /$ $\mathrm{kg}$ dose in comparison to group $\mathrm{C}$ ) from mild to moderate damage as the sunitinib dose increased (Figure 7 and 8 ). However, the inflammatory changes were mild, similar to those in group B at low sunitinib doses and become moderate changes at the highest sunitinib dose $(140 \mathrm{mg} / \mathrm{kg}$ ) where tubular casts were observed (Figure 8 ) and were statistically significant above $50 \mathrm{mg} / \mathrm{kg}$ doses).

\section{Histopathology findings in heart, brain and spleen}

The heart tissues from the vehicle control group showed normal cardiomyocytes with no vascular or inflammatory changes (Figure 9). The cardiovascular tissue from mice treated with paracetamol showed mild vascular congestion and inflammatory changes such as myocyte coagulation (Figure 9). Sunitinib treatment resulted in mild vascular congestion (Figure 9) but no inflammatory changes were noted. The histopathology of the heart in the coadministration treated mice showed moderate vascular and inflammatory changes at 100 and $140 \mathrm{mg} / \mathrm{kg}$ which were significant $(\mathrm{p}<0.05)$ and included congested and dilated blood vessels (Figure 9). However, mice treated with the lower doses of sunitinib alone showed reduction in cardiotoxicity in relation to the paracetamol group, which ranged from no damage to moderate damage at the $25-80 \mathrm{mg} / \mathrm{kg}$ doses of sunitinib (Figure 10).

The neurohistopathology assessment demonstrated normal neuronal cells with no vascular or inflammatory changes after administration of saline or paracetamol. Some congestion of vessels at the 'cortical junction' as well as evidence of liquefactive necrosis was observed in mice treated with sunitinib alone at low doses $(\mathrm{p}<0.05$ 

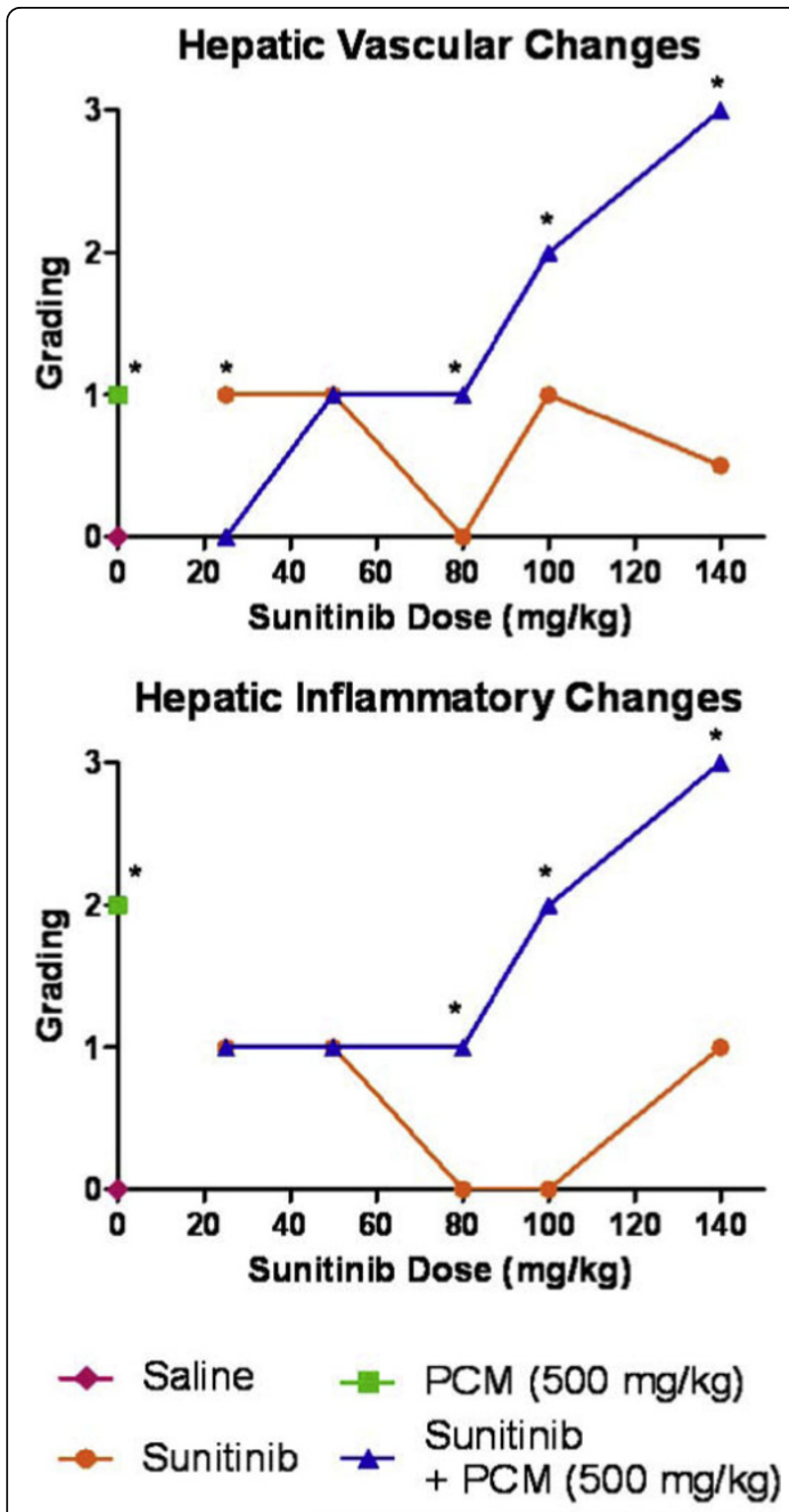

Figure 5 Hepatic vascular and inflammatory changes. Graphical representation of the score and grading of the vascular and inflammatory changes observed in the liver after administration of saline vehicle (baseline control), paracetamol, sunitinib at several doses or combination treatment paracetamol and sunitinib ${ }^{*} \mathrm{p}<$ 0.05 bewteen groups $C$ and D based on Mann Whitney test).

at 25 and $80 \mathrm{mg} / \mathrm{kg}$ ) but the toxicity decreased at high doses (Figure 11). The combination treatment group D, overall, showed less neurotoxicity than group $\mathrm{C}$ at low doses of sunitinib with lesser vascular congestion but a raise of neurotoxicity including generalised congestion was seen at high doses $(\mathrm{p}<0.05)$, of sunitinib in combination with paracetamol (Figure 12).

Finally, the histology assessment in the spleen did not reveal any vascular changes in the paracetamol treated group, sunitinib treated mice or the sunitinib- paracetamol drug combination group. Only a very slight splenic congestion was observed at the highest dose of $140 \mathrm{mg} / \mathrm{kg}(\mathrm{p}<0.05)$ sunitinib-paracetamol combination (Figure 13). Furthermore, no inflammatory changes were observed at any dose in the sunitinib alone group, paracetamol alone group, or in the sunitinib plus paracetamol drug combination group.

\section{Discussion}

The histopathological changes in the liver, kidneys, heart, brain and spleen together with hepatic and renal function biochemical markers were evaluated after coadministration of sunitinib with paracetamol. Clinical trials in mRCC patients had shown that liver and renal functions are affected by sunitinib leading to elevated AST, ALT and creatinine plasma levels [11]. Furthermore, the wide-spread use of paracetamol in cancer patients as an effective pain management drug with its potential renal and hepatotoxicity may elevate the risk of organ dysfunction after coadministration [10], a phenomenon observed with other anticancer drugs [9].

\section{Possible hepatoprotective effect of sunitinib}

In the current study, a significant rise in serum AST and ALT levels was observed after administration IP of 500 $\mathrm{mg} / \mathrm{kg}$ paracetamol dose in comparison with the baseline control group (Figure 1). This is a consistent finding with previous studies where it was shown that the rise in serum AST and ALT concentrations peak $4 \mathrm{~h}$ after administration of $500 \mathrm{mg} / \mathrm{kg}$ paracetamol IP [36]. In addition, the histopathological analysis also showed vascular and inflammatory changes (Figure 2) such as centrilobular necrosis, congested sinusoids and nuclear changes which were similar to other studies [35]. In contrast, after sunitinib was administered at escalating doses, the serum AST and ALT levels were only slightly elevated and mild liver damage with slight vascular congestion and signs of hepatocyte regeneration were found (Figure 3). No studies have yet been conducted on the histopathology changes caused by sunitinib administration; however, it was observed in clinical studies conducted on patients receiving sunitinib for the treatment of GIST or mRCC a slight increase in ALT and AST serum concentrations $[11,12]$. In addition, the combination treatment group showed. lower AST and ALT serum levels in comparison to group B (paracetamol, $500 \mathrm{mg} / \mathrm{kg}$, IP) at low doses of sunitinib coadministered with paracetamol. However, at higher doses of sunitinib in group D, both the AST and ALT levels were significantly increased (Figure 1). The histopathological analysis of the hepatic tissue showed a similar trend. At low doses of sunitinib coadministered with paracetamol, the hepatic morphological changes showed less severe damage compared to group B. Meanwhile, at higher 


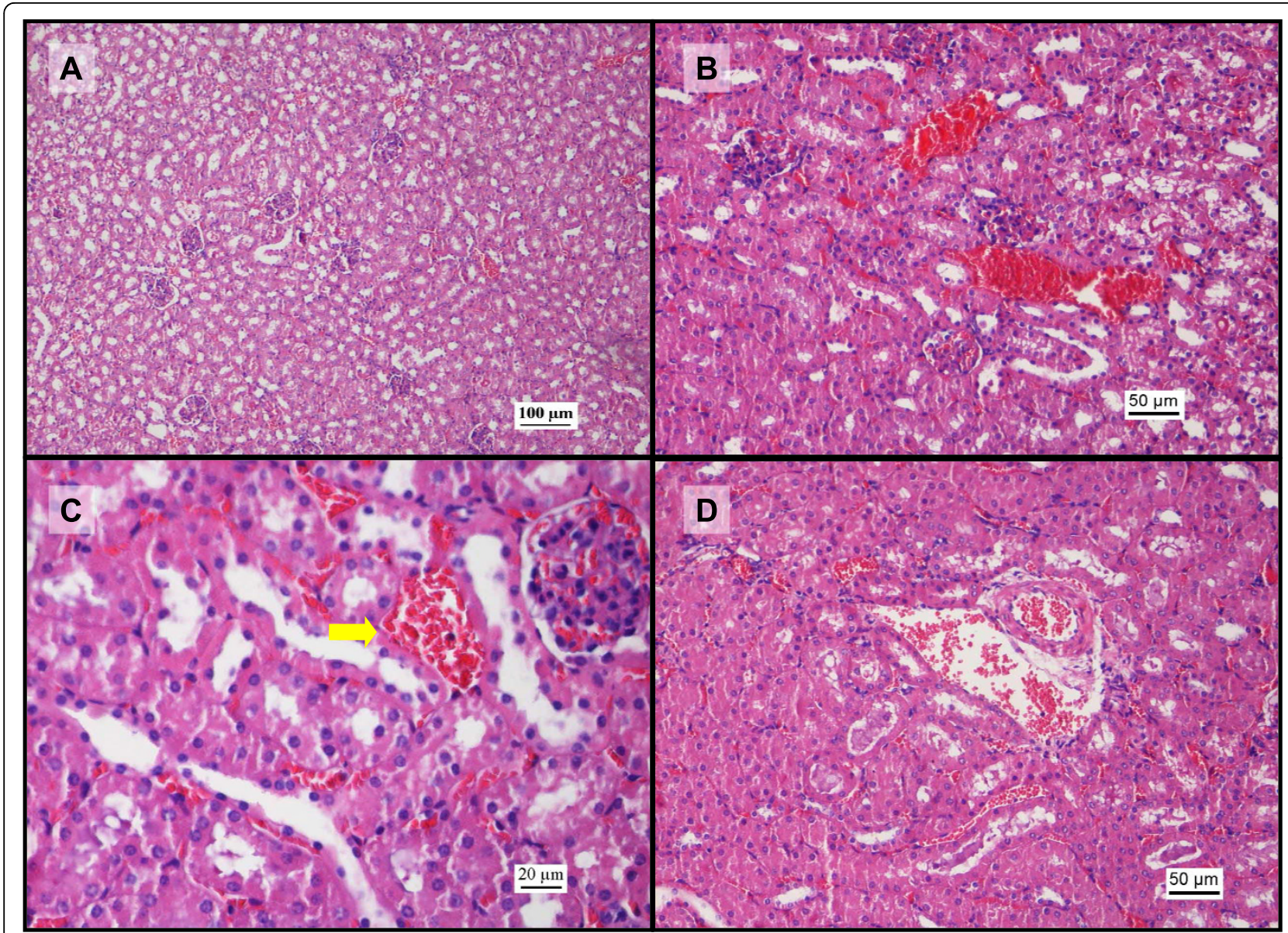

Figure 6 Histopathological changes in kidney after administration of paracetamol (H\&E staining). Photomicrographs of kidney tissue sections after administration of vehicle or paracetamol. A: (100x) saline group showing normal orientation of nephrons with adequate glomeruli and well spaced tubules. B: Photomicrograph (200x) showing areas of red blood cells extravasating into the interstitium and amidst the spaces between the tubules. C: photomicrograph (400x) showing congested vasculature (arrow) in the juxtaglomerular spaces. D: photomicrograph (200x) where dilated spaces filled with accumulated blood cells, suggesting focal haemorrhages can be observed.

doses of sunitinib (group D), a greater severity of the morphological changes such as vascular congestion, fatty change, and centrilobular necrosis were observed, indicating increased toxicity (Figure 5).

The biochemical and histopathological findings of the liver were unexpected. Low doses of sunitinib and paracetamol in the coadministration group seemed to decreased paracetamol hepatotoxicity, suggesting that sunitinib may have some level of hepatoprotective effect as previously suggested [10]. However, in the present study, the protective effect seemed to be obliterated at higher doses of sunitinib coadministered with paracetamol.

Therefore, a preliminary mechanistic working-hypothesis based on the paracetamol metabolic pathway may be postulated in the attempt to explain the differential effect between the low and the high doses of sunitinib upon coadministration with paracetamol. The metabolism of paracetamol is mediated by CYP2E1, $1 \mathrm{~A} 2$ and $3 \mathrm{~A} 4$ to form the toxic metabolite NAPQI [37], while sunitinib is metabolized by CYP3A4, 1A1 and 1A2 to form the active metabolite SU12662 [13,30]. Thus, as both sunitinib and paracetamol share the same isoenzyme CYP3A4 for their metabolism, the generation of NAPQI from this pathway may be decreased, resulting in less toxic effects. However, as the dose of sunitinib coadministered with paracetamol is increased, the protective effect is reversed and greater toxicity is observed. This could be explained if sunitinib or its metabolite affect the glutathione mediated detoxification pathway of paracetamol, either by binding to glutathione or by decreasing its available pool reducing the capacity to protect the hepatocytes from the electrophilic damage caused by NAPQI [38]. Then, even after lower generation of NAPQI , the depletion of glutathione available would lead to NAPQI accumulation and toxicity. Although conjugation of sunitinib with glutathione is not 


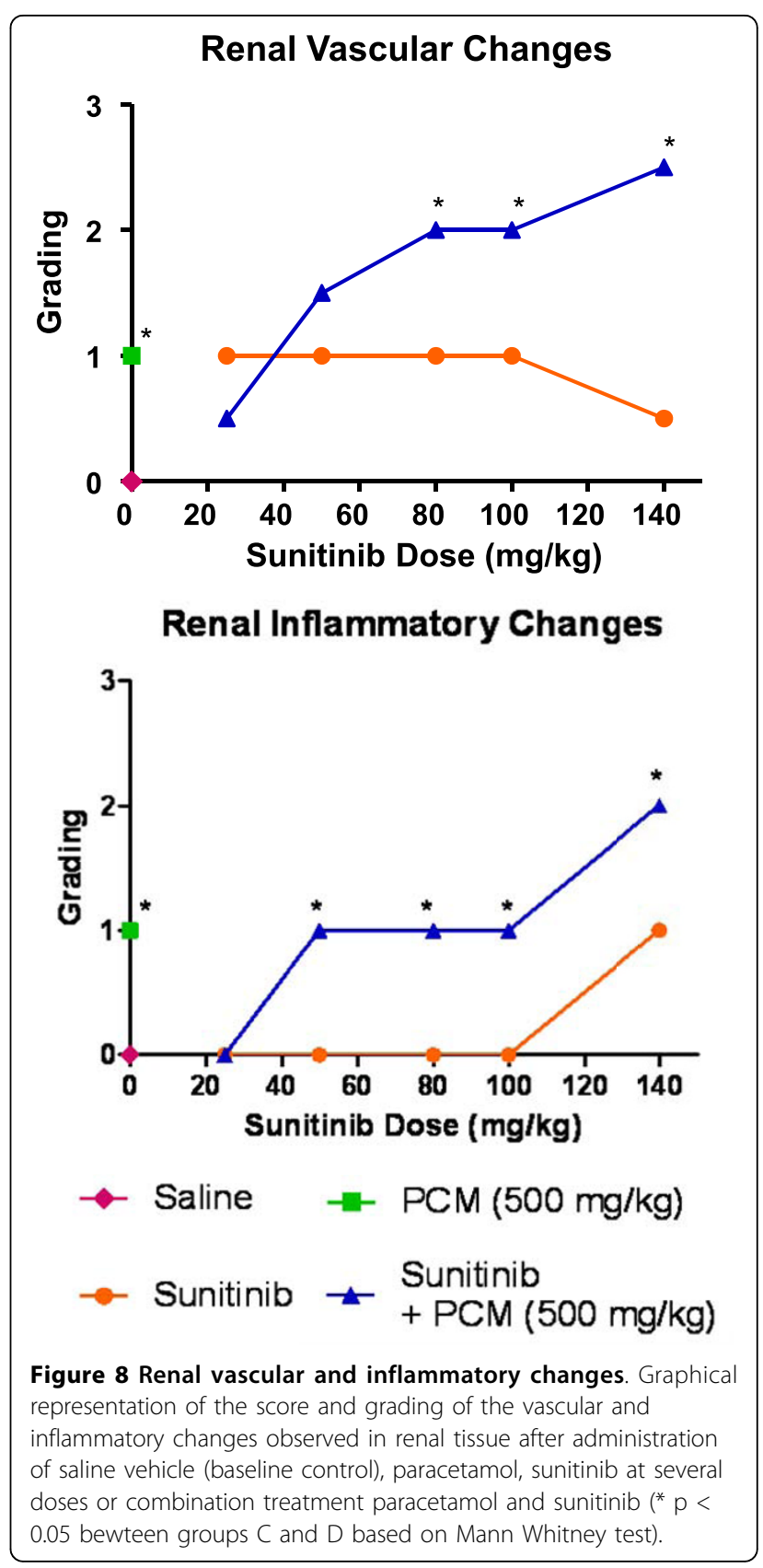

Figure 7 Representative histopathological changes in kidney after administration of sunitinib alone or coadministered with paracetamol (H\&E staining).

Photomicrographs of kidney tissue sections after administration of sunitinib or sunitinib and paracetamol. A: (200x) photomicrograph after administration of sunitinib $(50 \mathrm{mg} / \mathrm{kg})$ showing glomeruli atrophy (yellow arrow). Notice the reduction in size and cellularity, when compared to normal glomeruli (blue arrow). B: photomicrograph (100x) after administration of sunitinib $(80 \mathrm{mg} / \mathrm{kg})$ showing glomerular atrophy admixed with congested spaces and extravasated red blood cells in the interstitium. C: photomicrograph (200x) after coadministration of sunitinib $(140 \mathrm{mg} / \mathrm{kg})$ and paracetamol, showing tubules filled with casts in the lumen (arrow). reported in the literature, sunitinib is a substrate and a competitive inhibitor of a glutathione-conjugate transporter and may decrease the availability of glutathione in the hepatocytes [39]. A similar mechanistic explanation has been proposed for cisplatin, a chemotherapy drug which binds to glutathione [40]. Although the current experiment was not designed to evaluate the potential hepatoprotective effect of sunitinib in a paracetamol induced liver toxicity model, the results point out towards a certain protective effect as observed previously (10). Further studies need to be conducted to clarify the 


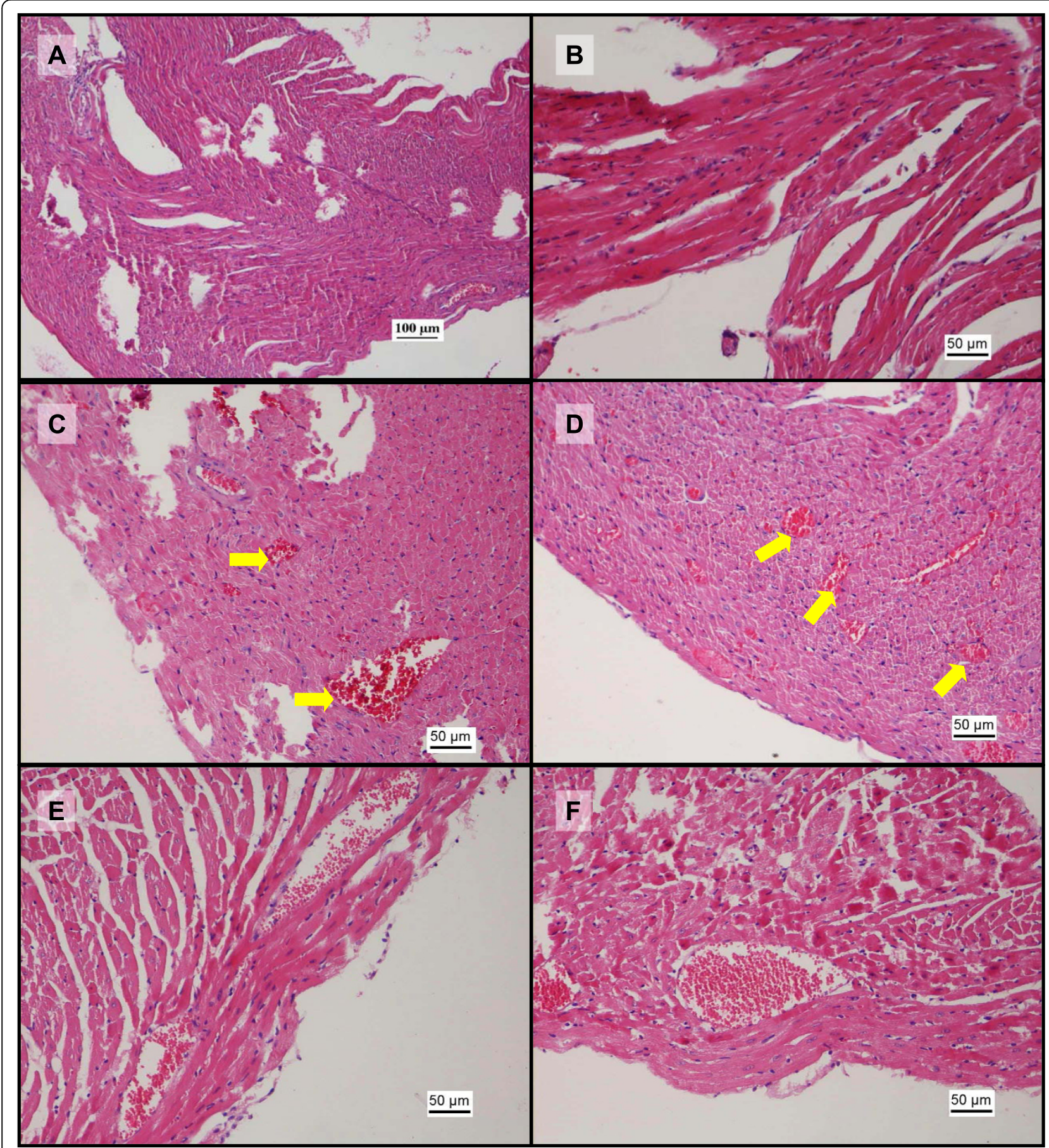

Figure 9 Photomicrographs of representative histopathological changes in heart tissue (H\&E staining). Photomicrographs of kidney tissue sections after administration of sunitinib or sunitinib and paracetamol. A: photomicrograph (100x) from heart tissue from the control saline group showing the ventricular wall with normal orientation of healthy cardiomyocytes. B: photomicrograph (200x) from the saline vehicle group showing the normal morphology of the muscle fibers with abundant wavy cytoplasm and small nuclei. C: photomicrograph (200x) after administration of paracetamol showing numerous congested vessels (arrows) amidst the muscle fibres. D: photomicrograph (200x) showing congested and dilated blood vessels (arrows) in the heart muscle filled with red blood cells after administration of $50 \mathrm{mg} / \mathrm{kg}$ sunitinib. E: photomicrograph (200x) showing congested and dilated blood vessels in the heart muscle after coadministration of $80 \mathrm{mg} / \mathrm{kg}$ sunitinib with paracetamol. F: photomicrograph (200x) showing further congested and dilated blood vessels in the heart muscle and filled with red blood cells after coadministration of sunitinib $(100 \mathrm{mg} / \mathrm{kg})$ and paracetamol. 


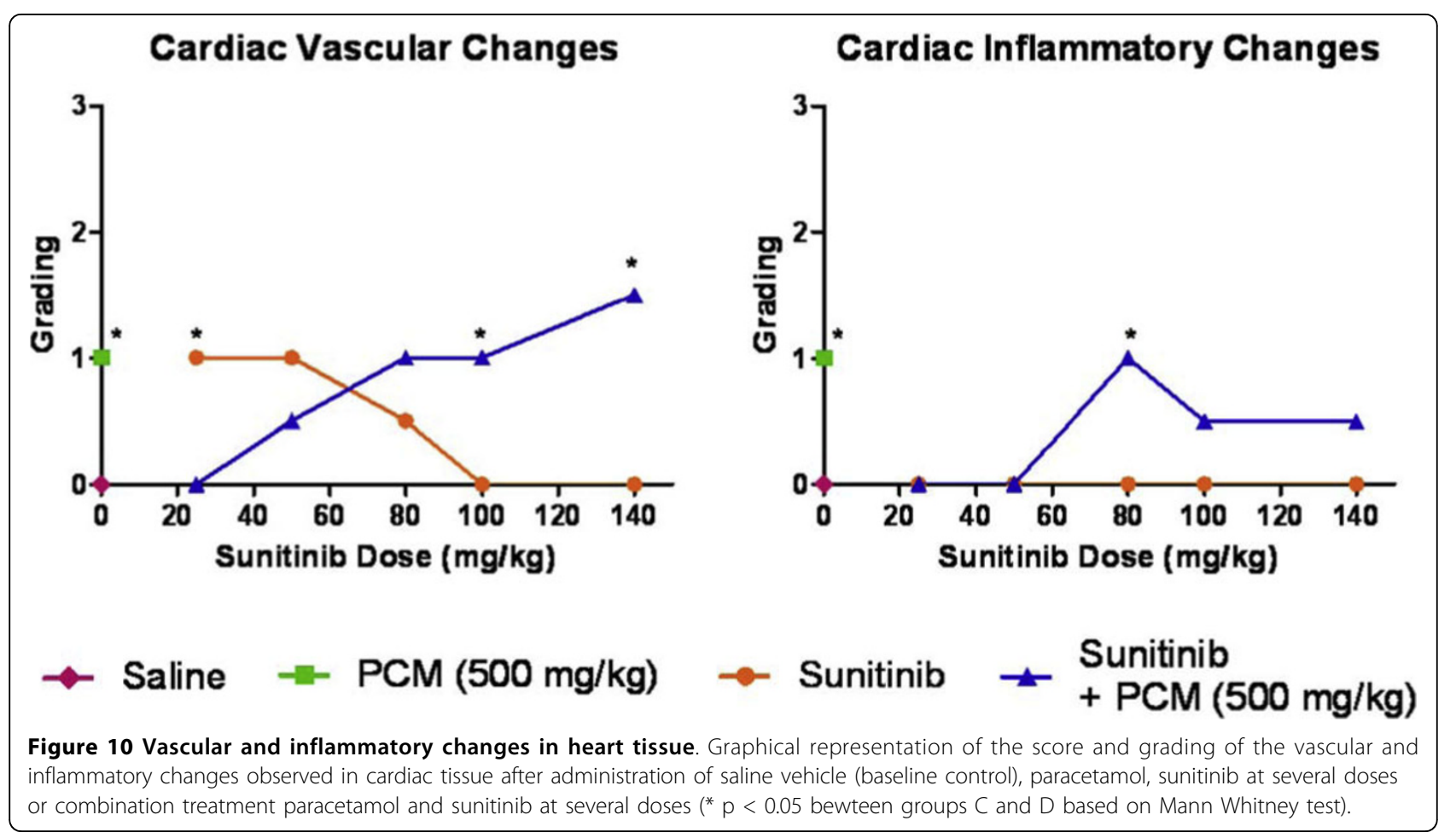

intertwining relationship between paracetamol, sunitinib, the formation of NAQPI and the glutathione cellular concentration.

\section{Renal toxicity}

The biochemical markers BUN and creatinine were used to evaluate renal function. Administration of $500 \mathrm{mg} / \mathrm{kg}$ paracetamol IP caused a significant rise in BUN concentrations (Figure 1) which was consistent with other studies after oral [41] or IP administration [42] of paracetamol, although the biomarker concentrations were measured at a later time point $(24 \mathrm{~h})$. The toxicity associated with paracetamol also resulted in glomerular atrophy and necrosis of the tubules, similar to those observed in acute tubular necrosis in both proximal and distal parts of the tubules including damage to the glomerulus (Figure 6) [41,43]. Administration of sunitinib caused a small elevation of BUN levels and mild vascular congestion at the highest dose $(140 \mathrm{mg} / \mathrm{kg})$. When sunitinib was coadministered with paracetamol, the BUN plasma levels and the histopathological analysis at low doses of sunitinib were similar to those of paracetamol treated group suggesting that the toxicity may be due to the presence of paracetamol only. Besides, the circulating paracetamol toxic metabolite may be generated in the liver as well at the proximal tubule of the kidney by the CYP2E1 enzyme [44]. However, at higher doses of sunitinib, the BUN plasma concentrations rose above those of observed in the groups that were given paracetamol or sunitinib alone and was accompanied by increased vascular and inflammatory changes (Figure 8). This suggests that the renal toxicity observed at higher doses may be a combined effect of the toxicity contributed by sunitinib and paracetamol.

A significant correlation between the BUN levels and kidney morphological changes was present (Table 2). However, the creatinine biomarker did not show any correlation with the histopathological findings. This finding is similar to other studies where no significant rise in plasma creatinine level was noted $6 \mathrm{~h}$ after paracetamol administration at higher doses [45]. Thus, creatinine plasma levels may not be an early indicator of renal toxicity, even though histopathological changes were observed in the kidneys [46,47].

The protective effect of sunitinib on paracetamol toxicity was not as obvious in the kidneys as it was in the liver. This may be due to additional mechanisms contributing to paracetamol toxicity such as prostaglandin synthetase and N-deacetylase enzymes [29], different mechanisms and sensitivity of the renal tissue [48] or different in situ biotransformation [49]. Consequently, sunitinib may not be able to affect the paracetamol metabolic pathway in the kidneys.

\section{Associated toxicity in heart, spleen and brain}

Several studies carried out in humans with sunitinib have reported signs of toxicity in other organs besides the liver or the kidneys [50]. 


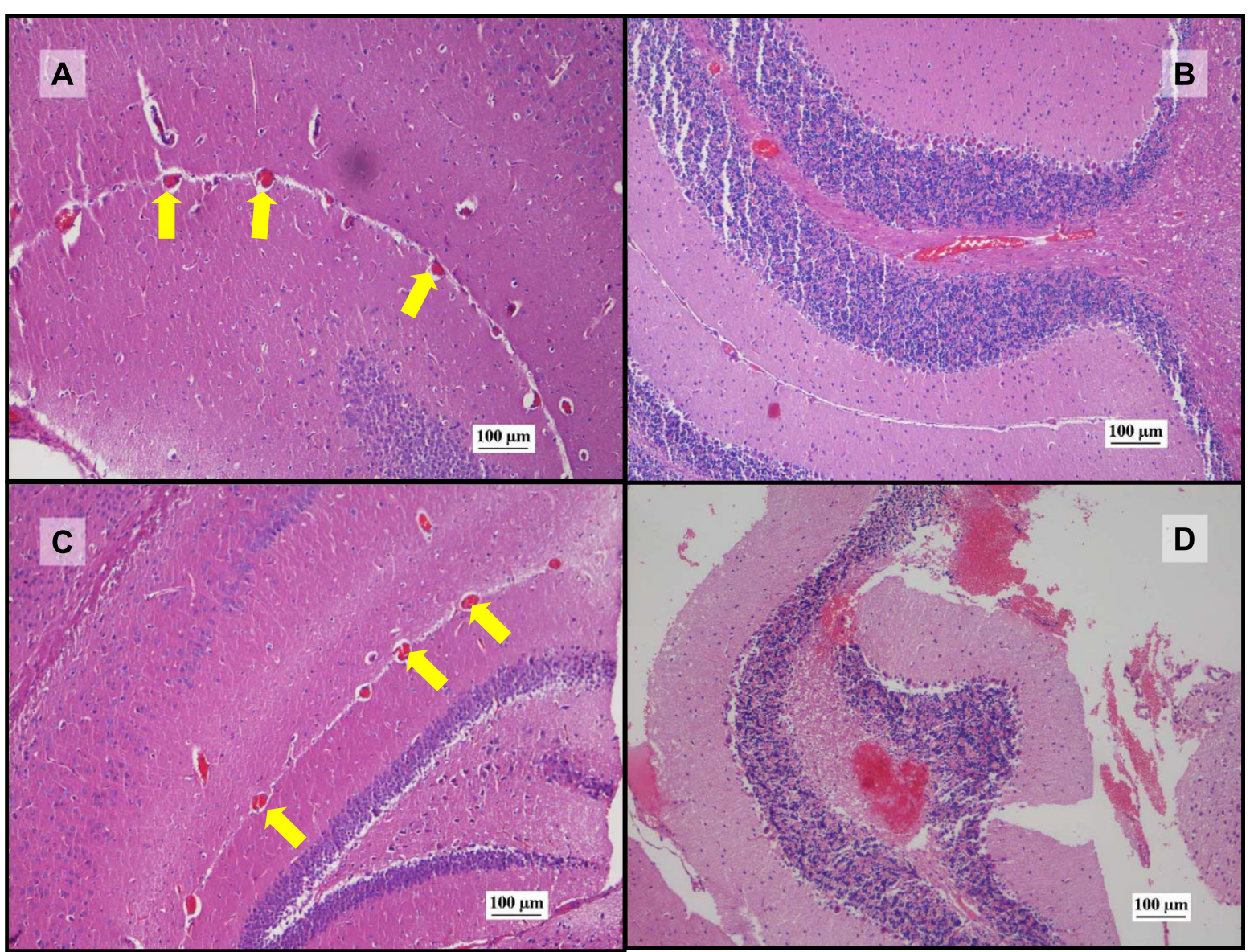

Figure 11 Photomicrographs of representative histopathological changes in brain tissue (H\&E staining, 100x). Photomicrographs of representative brain regions after administration of sunitinib or combination treatment of sunitinib and paracetamol. A: photomicrograph showing zones of congested blood vessels of moderate to small size (arrows) bordering the cellular areas after administration of sunitinib 50 $\mathrm{mg} / \mathrm{kg}$ dose. B: photomicrograph from the sunitinib $80 \mathrm{mg} / \mathrm{kg}$ group showing vascular congestion in the brain. C: photomicrograph from the combination treatment sunitinib $(50 \mathrm{mg} / \mathrm{kg}$ ) and paracetamol group showing vascular congestion (arrows) in the brain. D: photomicrograph showing vascular congestion in the brain after coadministration of sunitinib $100 \mathrm{mg} / \mathrm{kg}$ and paracetamol.

In the present study, sunitinib treatment showed vascular congestion in the heart with no inflammatory changes in the cardiomyocytes (Figure 9). These results are consistent with observations in clinical studies where the cardiotoxicity did not present inflammatory or fibrotic changes in patients [23]. Some of the mechanisms of cardiotoxicity for other tyrosine kinase inhibitors have been determined, but the mechanism of cardiotoxicity due to sunitinib is yet to be discovered [51]. Although paracetamol cardiotoxicity is rare, non-specific ECG changes, bradycardia, pericardial rub and endocarditis, were observed in patients [52]. Furthermore, subendocardial haemorrhages and muscle necrosis was noted in the autopsies of two patients who died from paracetamol overdose [53]. Mice in the paracetamol treatment group showed signs of toxicity with congested vessels and focal myocyte coagulation (Figure 9). It has been suggested that these toxicity pattern may be associated with paracetamol metabolite and free radical NAPQI, resulting in myocyte glutathione depletion, damage to the myocardium and breakdown of endothelium-derived vascular relaxing factor (EDRF), leading to functional coronary insufficiency [33] and myocyte coagulative necrosis which has been observed in our study and in previous ones [52]. The combination treatment also showed dose dependent cardiac toxicity with a pattern similar to that observed in liver: At low doses of sunitinib in the drug combination, the scoring of the morphological changes was below that of paracetamol alone, while the toxicity increased slightly at the higher doses of sunitinib with paracetamol. Extrahepatic paracetamol toxicity in kidneys, lungs and nasal glands has been attributed to circulating NAPQI generated in the liver [49]. Thus, it is possible to suggest that the cardiotoxicity may be associated with the generation of toxic metabolite by the liver 


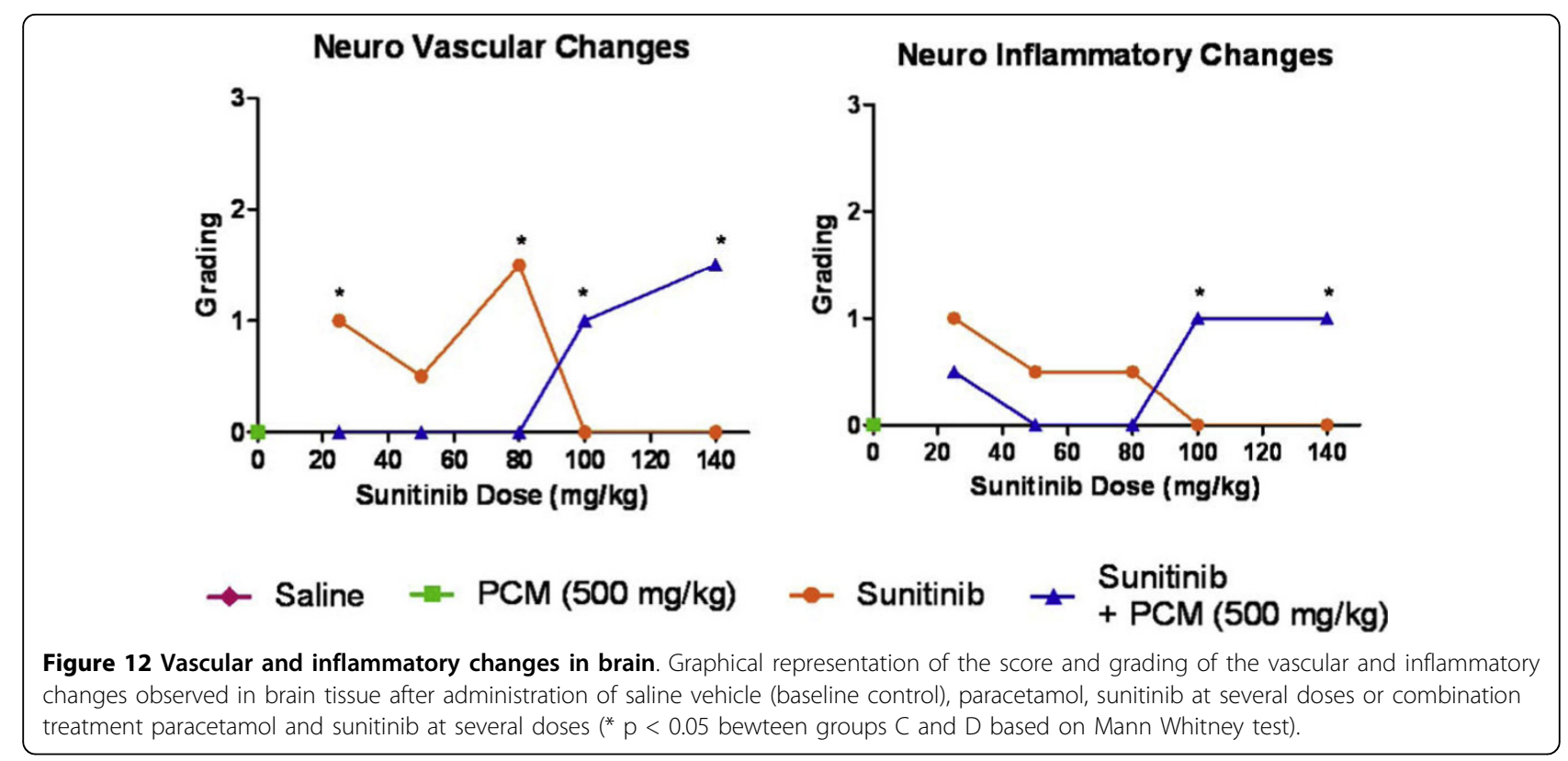

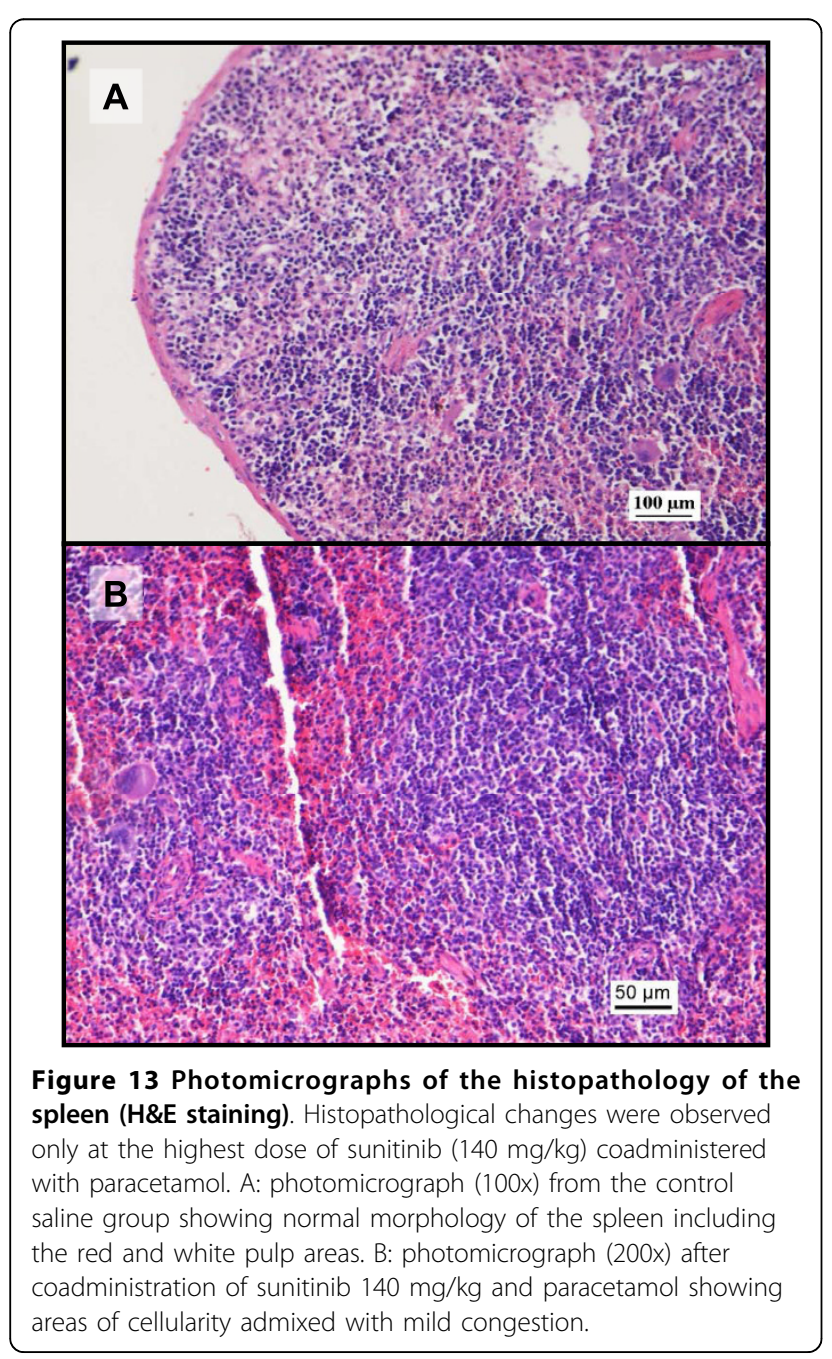

and would follow the liver pattern of toxicity as proposed with the working hypothesis [36]. Further studies, including cardiac biomarkers such as CK-MB and quantification of circulating NAPQI are needed to assess sunitinib effects on the cardiac toxicity.

There was no evidence of neurotoxicity associated with paracetamol [54]. However, sunitinib caused vascular and inflammatory changes including vascular congestion and early signs of liquefactive necrosis (Figure 11). Previous animal studies have confirmed that sunitinib and its metabolite penetrate the brain up to $30 \%-40 \%$ of plasma concentrations in monkeys [55], 4-7 times the plasma concentration in mice [21]. In fact, some patients developed cognitive and behavioural changes during sunitinib treatment that included disorientation, confusion and word-finding difficulties [56] and posterior reversible encephalopathy syndrome in one patient [27]. These symptoms were reversible upon sunitinib discontinuation $[27,56]$ but the mechanisms leading the development of neurological symptoms due to tyrosine kinase inhibition remain unknown [54]. At low doses of

Table 2 Significant values of the correlation between biomarkers and liver and renal histopathological changes based on Spearman rank correlation test

\begin{tabular}{lcccc}
\hline Biomarker & \multicolumn{2}{c}{ Liver changes } & \multicolumn{2}{c}{ Kidney changes } \\
\cline { 2 - 5 } & Vascular & Inflammatory & Vascular & Inflammatory \\
\hline AST & $\mathrm{p}<0.01$ & $\mathrm{p}<0.01$ & $\mathrm{n} / \mathrm{a}$ & $\mathrm{n} / \mathrm{a}$ \\
ALT & $\mathrm{p}<0.01$ & $\mathrm{p}<0.01$ & $\mathrm{n} / \mathrm{a}$ & $\mathrm{n} / \mathrm{a}$ \\
BUN & $n / a$ & $n / a$ & $p<0.01$ & $\mathrm{p}<0.01$ \\
Creatinine & $n / a$ & $n / a$ & $p>0.05$ & $\mathrm{p}>0.05$ \\
\hline
\end{tabular}

The correlation is significant if $p<0.01$. 
sunitinib coadministered with paracetamol, the morphological changes were lesser to those observed in the sunitinib alone treatment group which is consistent with previous findings suggesting anti-oxidant and antiinflammatory effect of paracetamol on the cerebrovasculature due to menadione-induced oxidative stress [57]. Furthermore, the decreased toxicity observed in this study may be supported by lower sunitinib brain concentration after coadministration with paracetamol observed in a separate study $[58,59]$. However, when high doses of sunitinib were administered with paracetamol, the vascular congestion severity increased and liquefactive necrosis was noted suggesting other mechanisms of toxicity which are unknown.

Finally, there were no signs of toxicity in the spleen in all groups except at $140 \mathrm{mg} / \mathrm{kg}$ of sunitinib coadministered with paracetamol which mild splenic congestion was observed (Figure 13). Similar splenic congestion was also observed after barbiturate administration in dogs [60]. The absent of toxicity, except at a very high dose, may encourage the development of advanced particulate delivery systems to target specific sunitinib-sensitive tumours without the risk of toxicity associated to their accumulation in the spleen $[61,62]$.

\section{Correlation between biomarkers and histopathological findings}

Of especial interest is the ability to establish a correlation between toxicology and biomarkers that can provide early detection of toxicity and allow prompt intervention. In this study, we found a significant correlation $(\mathrm{p}<0.01)$ between the liver biochemical markers (ALT and AST) and the liver histopathology for both vascular $(\mathrm{p}<0.01)$ and inflammatory $(\mathrm{p}<0.01)$ changes (Table 2). A significant correlation was also found between the BUN plasma levels and kidney morphological changes be it vascular $(\mathrm{p}<0.01)$ or inflammatory $(\mathrm{p}<0.01)$ changes. This suggests that ALT and AST may be used as early indicators for the detection of acute liver damage as well as BUN for renal toxicity in the treatment of sunitinib and paracetamol.

However, there was no correlation with creatinine plasma levels. This was found consistent with other studies where no significant rise in plasma creatinine level was noted 6 hours after paracetamol administration at higher dose [44]. Thus, this finding suggests that unlike BUN, creatinine may not be an early indicator of renal toxicity or that 4 hours is too early to observe any significant rise in creatinine levels $[30,45]$.

\section{Conclusions}

The present study has found changes in the toxicity pattern with the coadministration of paracetamol with sunitinib compared to sunitinib alone.
Sunitinib administration resulted in mild toxicity in the liver, kidneys, heart and brain, asserting its safety at low doses. The coadministration of sunitinib and paracetamol had dose and differential effects in liver, kidneys and heart. However, no toxicity was observed in the spleen and neurotoxicity was observed only when sunitinib was administered alone. Sunitinib also seemed to display dose dependent, protective effects on paracetamol toxicity, especially regarding hepatotoxicity, which may be related to the fact that both paracetamol and sunitinib share the biotransformation pathway.

A significant correlation between the liver biomarkers (ALT and AST) and hepatic histopathological changes was found as well as between the renal biomarker BUN and kidney morphological changes. However, creatinine levels did not show a correlation with any study group. This suggests that ALT, AST and BUN may be valid early indicators for monitoring emerging toxicity in patients undergoing treatment with sunitinib and paracetamol.

\section{Acknowledgements}

The authors would like to acknowledge Ms NorBazlin Md Marham and Ms Amy Saik for technical assistance as well as the International Medical University for funding, grant \# BMS 101-2009(09).

\section{Author details}

${ }^{1}$ Department of Human Biology, School of Medicine, International Medical University, Jalan 19/155B, Bukit Jalil, 57000 Kuala Lumpur, Malaysia.

${ }^{2}$ Department of Pharmaceutical Technology, School of Pharmacy and Health Sciences, International Medical University, Jalan 19/155B, Bukit Jalil, 57000 Kuala Lumpur, Malaysia. ${ }^{3}$ Department of Pathology, International Medical University, Jalan 19/155B, Bukit Jalil, 57000 Kuala Lumpur, Malaysia.

\section{Authors' contributions}

All authors contributed to the development of the project, the realization, the critical analysis and interpretation of the results. All authors reviewed and approved the manuscript.

\section{Competing interests}

The authors declare that they have no competing interests.

Received: 5 April 2010 Accepted: 15 October 2010

Published: 15 October 2010

\section{References}

1. Scripture CD, Figg WD: Drug interactions in cancer therapy. Nat Rev Cancer 2006, 6:546-58.

2. Riechelmann RP, Giglio AD: Drug interactions in oncology: How common are they? Ann Oncol 2009, 20:1907-1912.

3. Riechelmann RP, Tannock IF, Wang L, Saad ED, Taback NA, Krzyzanowska MK: Potential drug interactions and duplicate prescriptions among cancer patients. J Natl Cancer Inst 2007, 99:592-600.

4. Christo PJ, Mazloomdoost D: Cancer pain and analgesia. Ann N Y Acad Sci 2008, 1138:278-98.

5. Weiss SC, Emanuel LL, Fairclough DL, Emanuel EJ: Understanding the experience of pain in terminally ill patients. The Lancet 2001, 357:1311-1315.

6. Ridruejo E, Cacchione R, Villamil AG, Marciano S, Gadano AC, Mando OG: Imatinib-induced fatal acute liver failure. World J Gastroenterol 2007, 13:6608-6611.

7. Nassar I, Pasupati T, Judson JP, Segarra I: Reduced exposure of imatinib after coadministration with acetaminophen to mice. Ind J Pharmacol 2009, 41:167-172. 
8. Nassar I, Pasupati T, Judson JP, Segarra I: Histopathological study of the hepatic and renal toxicity associated with the coadministration of imatinib and acetaminophen in a preclinical mouse model. Malays J Path 2010, 32:1-11[http://www.mjpath.org.my/2010.1/coadministration_Imatinib_Acetaminophen.pdf].

9. Weise AM, Liu CY, Shields AF: Fatal liver failure in a patient on acetaminophen treated with sunitinib malate and levothyroxine. Ann Pharmacother 2009, 43:761-766.

10. Goodman VL, Rock EP, Dagher R, Ramchandani RP, Abraham S, Gobburu JVS, Booth BP, Verbois SL, Morse DE, Liang CY, Chidambaram N, Jiang JX, Tang S, Mahjoob K, Justice R, Pazdur R: Approval summary: Sunitinib for the treatment of imatinib refractory or intolerant gastrointestinal stromal tumors and advanced renal cell carcinoma. Clin Cancer Res 2007, 13:1367-1373.

11. Motzer RJ, Hutson TE, Tomczak P, Michaelson MD, Bukowski RM, Oudard S, Negrier S, Szczylik C, Pili R, Bjarnason GA, Garcia-del-Muro X, Sosman JA, Solska E, Wilding G, Thompson JA, Kim ST, Chen I, Huang X, Figlin RA: Overall survival and updated results for sunitinib compared with interferon alfa in patients with metastatic renal cell carcinoma. J Clin Oncol 2009, 27:3584-3590.

12. Hiles JJ, Kolesar JM: Role of sunitinib and sorafenib in the treatment of metastatic renal cell carcinoma. Am J Health-Syst Pharm 2008, 65:123-131.

13. Mendel DB, Laird AD, Xin X, Louie SG, Christensen JG, Li G, Schreck RE, Abrams TJ, Ngai TJ, Lee LB, Murray LJ, Carver J, Chan E, Moss KG, Haznedar JO, Sukbuntherng J, Blake RA, Sun L, Tang C, Miller T, Shirazian S, McMahon G, Cherrington JM, et al: In vivo Antitumor Activity of SU11248 a Novel Tyrosine Kinase Inhibitor Targeting Vascular Endothelial Growth Factor and Platelet derived Growth Factor Receptors: Determination of a Pharmacokinetic/pharmacodynamic Relationship. Clin Cancer Res 2003, 9:327-337

14. O'Farrell AM, Abrams TJ, Yuen HA, Ngai TJ, Louie SG, Yee KW, Wong LM, Hong W, Lee LB, Town A, Smolich BD, Manning WC, Murray LJ, Heinrich MC, Cherrington JM: SU11248 is a novel FLT3 tyrosine kinase inhibitor with potent activity in vitro and in vivo. Blood 2003, 101:3597-3605.

15. Abrams TJ, Lee LB, Murray LJ, Pryer NK, Cherrington JM: SU11248 inhibits KIT and platelet derived growth factor receptor $\beta$ in preclinical models of human small cell lung cancer. Mol Cancer Ther 2003, 2:471-478.

16. Roskoski R: Sunitinib: a VEGF and PDGF receptor protein kinase and angiogenesis inhibitor. Biochem Biophys Res Commun 2007, 356:323-328.

17. Murray LJ, Abrams TJ, Long KR, Ngai TJ, Olson LM, Hong W, Keast PK, Brassard JA, O'Farrell AM, Cherrington JM, Pryer NK: SU1124208 inhibits tumor growth and CSF1R-dependent osteolysis in an experimental breast cancer bone metastasis model. Clin Exp Metastasis 2003, 757-766.

18. Faivre S, Delbaldo, Vera K, Robert C, Lozahic S, Lassau N, Bello C, Deprimo S, Brega N, Massimini G, Armand JP, Scigalla P, Raymond E: Safety, pharmacokinetic, and antitumor activity of SU1124248, a Novel Oral multitarget tyrosine kinase inhibitor, in patients with cancer. J Clin Onco 2006, 25-35

19. Chow LQM, Eckhardt SG: Sunitinib: from rational design to clinical efficacy. J Clin Oncol 2007, 25:884-896.

20. Haznedar J, Patyna S, Bello CL, Peng G, Speed W, Yu XM, Zhang QL, Sukbuntherng J, Sweeny D, Antonian L, Wu E: Single and multiple dose disposition kinetics of sunitinib malate, a multitargeted receptor tyrosine kinase inhibitor: comparative plasma kinetics in non-clinical species. Cancer Chemother Pharmacol 2008, 64:691-706.

21. Bello CL, Sherman L, Zhou J, Verkh L, Smeraglia J, Mount J, Klamerus KJ: Effect of food on the pharmacokinetics of sunitinib malate (SU1124178), a multi targeted receptor tyrosine kinase inhibitor: results from a phase I study in healthy subjects. Anti-Cancer Drugs 2006, 353-358.

22. Chu TF, Rupnick MA, Kerkela R, Dallabrida SM, Zurakowski D, Nguyen L, Woulfe K, Pravda E, Cassiola F, Desai J, George S, Morgan JA, Harris DM, Ismail NS, Chen JH, Schoen FJ, Van den Abbeele AD, Demetri GD, Force T, Chen $\mathrm{MH}$ : Cardiotoxicity associated with tyrosine kinase inhibitor sunitinib. Lancet 2007, 370:2011-2019.

23. Rini BI, Tamaskar I, Shaheen P, Salas R, Garcia J, Wood L, Reddy S, Dreicer R, Bukowski RM: Hypothyroidism in patients with metastatic renal cell carcinoma treated with sunitinib. J Natl Cancer Inst 2007, 99:81-83.

24. Lacouture ME, Reilly LM, Gerami P, Guitart J: Hand foot skin reaction in cancer patients treated with the multikinase inhibitors sorafenib and sunitinib. Ann Oncol 2008, 19:1955-1961.
25. Britten CD, Kabbinavar F, Hecht JR, Bello CL, Li J, Baum C, Slamon D: A phase I and pharmacokinetic study of sunitinib administered daily for 2 weeks, followed by a 1-week off period. Cancer Chemother Pharmacol 2008, 61:515-524.

26. Medioni J, Cojocarasu O, Banu E, Queudeville AC, Halimi P, Oudard S: Reversible encephalopathy syndrome secondary to sunitinib for metastatic cell carcinoma patient. Targ Oncol 2007, 2:193-195.

27. Demetri GD, van Oosterom AT, Garrett CR, Blackstein ME, Shah MH, Verweij J, McArthur G, Judson IR, Heinrich MC, Morgan JA, Desai J, Fletcher CD, George S, Bello CL, Huang X, Baum CM, Casali PG: Efficacy and safety of sunitinib in patients with advanced gastrointestinal stromal tumour after failure of imatinib: a randomised controlled trial. Lancet 2006, 368:1329-1338.

28. Nicholaou T, Wong R, Davis ID: Tumour lysis syndrome in a patient with renal-cell carcinoma treated with sunitinib malate. Lancet 2007, 369:1923-1924.

29. van Erp NP, Gelderblom H, Guchelaar HJ: Clinical pharmacokinetics of tyrosine kinase inhibitors. Cancer Treat Rev 2009, 35:692-706.

30. Mazer M, Perrone J: Acetaminophen-induced nephrotoxicity: Pathophysiology, clinical manifestations, and management. J Med Toxicol 2008, 4:2-6.

31. Pakravan N, Bateman DN, Godddard J: Effect of acute paracetamol overdose on changes in serum and urine electrolytes. $\mathrm{Br} J$ Clin Pharmacol 2007, 64:824-832.

32. Hinson JA, Roberts DW, James LP: Mechanisms of acetaminopheninduced liver necrosis. Handb Exp Pharmacol. 2010, 196:369-405.

33. Laine JE, Auriola S, Pasanen M, Juvonen RO: Acetaminophen bioactivation by human cytochrome P450 enzymes and animal microsomes. Xenobiotica 2009, 39:11-21.

34. Armour A, Slater SD: Paracetamol cardiotoxicity. Postgrad Med J 1993, 69:52-54.

35. Lee KH, Chen YS, Judson JP, Chakravarthi S, Sim YM, Er HM: The effect of water extracts of Euphorbia hirta on cartilage degeneration in arthritic rats. Malays J Pathol 2008, 30:95-102.

36. Yapar K, Kart A, Karapehlivan M, Atakisi O, Tunca R, Erginsoy S, Citil M: Hepatoprotective effect of L-carnitine against acute acetaminophen toxicity in mice. Exp Toxicol Pathol 2007, 59:121-128.

37. Manyike PT, Kharasch ED, Kalhorn TF, Slattery JT: Contribution of CYP2E1 and CYP3A to acetaminophen reactive metabolite formation. Clin Pharmacol Ther 2000, 67:275-282.

38. Franco R, Cidlowski JA: Apoptosis and glutathione: Beyond an antioxidant. Cell Death and Differ 2009, 16:1303-1314.

39. Singhal SS, Sehrawat $A$, Sahu M, Singhal $P$, Vatsyayan $R$, Lelsani $P C R$, Yadav S, Awasthi S: RLIP76 transports sunitinib and sorafenib and mediates drug resistance in kidney cancer. Int J Cancer 2009, 126:1327-1338.

40. Shimeda $Y$, Hirotani $Y$, Akimoto $Y$, Shindou K, ljiri $Y$, Nishihori T, Tanaka K: Protective effects of capsaicin against cisplatin-induced nephrotoxicity in rats. Biol Pharm Bull 2005, 28:1635-1638.

41. Ghosh A, Sil PC: Anti-oxidative effect of a protein from Cajanus indicus $L$ against acetaminophen-induced hepato-nephro toxicity. J Biochem $\mathrm{Mol}$ Bio 2007, 40:1039-1049.

42. Roomi MW, Kalinovsky T, Ivanov V, Rath M, Niedzwiecki A: A nutrient mixture prevents acetaminophen hepatic and renal toxicity in ICR mice. Hum Exp Toxicol 2008, 27:223-230.

43. Palani S, Raja S, Kumar RP, Jayakumar S, Kumar BS: Therapeutic efficacy of Pimpinella tirupatiensis (Apiaceae) on acetaminophen induced nephrotoxicity and oxidative stress in male albino rats. Int J PharmTech Res 2009, 1:925-934.

44. Liu H, Baliga R: Cytochrome P450 2E1 null mice provide novel protection against cisplatin-induced nephrotoxicity and apoptosis. Kidney Int 2003, 63:1687-1696.

45. Futter LE, al-Swayeh OA, Moore PK: A comparison of the effect of nitroparacetamol and paracetamol on liver injury. Br J Pharmacol 2001, 132:10-12.

46. Perrone RD, Madias NE, Levey AS: Serum creatinine as an index of renal function: New insights into old concepts. Clin Chem 1992, 38:1933-1953.

47. Pakravan N, Bateman DN, Godddard J: Effect of acute paracetamol overdose on changes in serum and urine electrolytes. Br J Clin Pharmacol 2007, 64:824-832. 
48. Von Mach MA, Hermanns-Clausen M, Koch I, Hengstler JG, Lauterbach M, Kaes J, Weilemann LS: Experiences of a poison centre network with renal insufficiency in acetaminophen overdose: An analysis of 17 cases. Clin Toxicol 2005, 43:31-37.

49. Sakuma T, Kawasaki Y, Jarukamjorn K, Nemoto N: Sex differences of drug metabolizing enzyme: Female predominant expression of human and mouse cytochrome P450 3A isoforms. J Health Sci 2009, 55:325-337.

50. Gu J, Cui H, Behr M, Zhang L, Zhang QY, Yang W, Hinson JA, Ding X: In vivo mechanisms of tissue-selective drug toxicity: Effects of liverspecific knockout of the NADPH-cytochrome P450 reductase gene on acetaminophen toxicity in kidney, lung, and nasal mucosa. Mol Pharmacol 2005, 67:623-630.

51. Chen MH, Kerkela R, Force T: Mechanisms of cardiomyopathy associated with tyrosine kinase inhibitor cancer therapeutics. Circulation 2008, 118:84-95.

52. Jones AL, Prescott LF: Unusual complications of paracetamol poisoning. QJ Med 1997, 90:161-168.

53. Will EJ, Tomkins AM: Acute myocardial necrosis in paracetamol poisoning. Br Med J 1971, 4:430-431.

54. Fischer $\amalg$, Green MD, Harman AW: Levels of acetaminophen and its metabolites in mouse tissues after a toxic dose. $J$ Pharmacol Exp Ther 1981, 219:281-286.

55. Patyna S, Peng G: Distribution of sunitinib and its active metabolite in brain and spinal cord tissue following oral or intravenous administration in rodents and monkeys. Eur J Cancer 2006, 4(Suppl 1):21.

56. van der Veldt AAM, van den Eertwegh AJM, Hoekman K, Barkhof F, Boven E: Reversible cognitive disorders after sunitinib for advanced renal cell cancer in patients with preexisting arteriosclerotic leukoencephalopathy. Ann Oncol 2007, 18:1747-1750.

57. Tripathy D, Grammas P: Acetaminophen protects brain endothelial cells against oxidative stress. Microvascular Res 2009, 77:289-296.

58. Koo TW: Effects of paracetamol on the pharmacokinetics and tissue disposition profiles of sunitinib after single oral dose coadministration in male mice. BPharm thesis International Medical University, Department of Pharmaceutical Technology, Kuala Lumpur 2009.

59. Liew MH: Effects of paracetamol on the pharmacokinetics and tissue distribution profiles of sunitinib after single oral dose coadministration to female ICR mice. BPharm thesis International Medical University, Department of Pharmaceutical Technology, Kuala Lumpur 2009.

60. O'Brien RT, Walker KR, Osgood TL: Sonographic features of drug-induced splenic congestion. Vet Radiol Ultrasound 2004, 45:225-227.

61. Medina OP, Zhu Y, Kairemo K: Targeted liposomal drug delivery in cancer. Curr Pharm Des 2004, 10:2981-2989.

62. Moo KS, Teoh M, Radhakrishnan S, Narayanan P, Bukhari NI, Segarra I: Disposition and tissue distribution of imatinib after intravenous bolus dose to mice in a liposome formulation. Acta Pharm Sinica 2010, 45:901-908

doi:10.1186/1471-2210-10-14

Cite this article as: Lim et al.: Histopathology and biochemistry analysis of the interaction between sunitinib and paracetamol in mice. BMC Pharmacology 2010 10:14.

\section{Submit your next manuscript to BioMed Central and take full advantage of:}

- Convenient online submission

- Thorough peer review

- No space constraints or color figure charges

- Immediate publication on acceptance

- Inclusion in PubMed, CAS, Scopus and Google Scholar

- Research which is freely available for redistribution

Submit your manuscript at www.biomedcentral.com/submit
Biomed Central 